\title{
A STUDY INTO THE VALIDITY OF THE SHIP DESIGN SPIRAL IN EARLY STAGE SHIP DESIGN
}

\author{
Rachel Pawling $^{1}$, David Andrews ${ }^{1}$ and Victoria Percival ${ }^{2}$ \\ ${ }^{1}$ Marine Research Group, Department of Mechanical Engineering, University College London (UCL) \\ ${ }^{2}$ MSc Student in UCL Department of Mechanical Engineering 2009-2010, currently appointed to her charge appointment as Marine \\ Engineer Officer on HMS DEFENDER
}

For many years the design spiral has been seen to be a convenient model of an acknowledged complex process. It has virtues particularly in recognising the interactive and, hopefully, converging nature of the process. However many find it unsatisfactory. One early criticism focused on its apparent assumption of a relatively smooth process to a balanced solution implied by most ship concept algorithms. The paper draws on a post-graduate design investigation using the UCL Design Building Block approach, which looked specifically at a nascent naval combatant design and the issues of size associated with "passing decks" and margins. Results from the study are seen to suggest there are distinct regions of cliffs and plateaux in plots of capability against design output, namely ship size and cost. These findings are discussed with regard to the insight they provide into the nature of such ship designs and different ways of representing the ship design process. The paper concludes that the ship design spiral is a misleading and unreliable representation of complex ship design at both the strategic and detailed iterative levels.

KeyWords: Computer Aided Preliminary Ship Design; Design Building Blocks; Design Spiral; Naval Combatants.

\section{INTRODUCTION}

As part of the general thrust of discussions on the nature of marine design, which has particularly been addressed in the tri-annual International Marine Design Conference (IMDC) fora, the ship design process has been the subject of specific focus. Within the overall structure of this process, divided as it is into distinct phases variously known as concept/initial/preliminary design followed by feasibility/assessment/embodiment design and then ship design/project definition and or possibly contract design/definition and with a final design phase of detailed design or build definition (see Gale 2003), there has been a desire to reflect, not just that these phases are of ever greater design definition but also that they all have an inherent pattern to them. This has been seen to be characterised by the model of the Design Spiral, whose origins in ship design are discussed in more detail in Section 3.

Initial or preliminary ship design is seen as the most crucial of the ship design phases, as it is that in which the primary design choices are made, hopefully from an exploratory process. Thus some $70 \%$ or more of the cost implications are committed then despite less than 5\% of the expenditure being made in this first phase. In the 1997 IMDC State of Art (SoA) Design Methodology Report (Andrews et al 1997) some 33 sources were referred to as addressing preliminary ship design (and another 64 that address the specific field of naval ship design - most of which were also focussed on the early stages of design). This was done to see if there was any pattern to the practice of preliminary ship design.
Two of the current paper's authors drew further on those publications in a 2008 paper (Andrews \& Pawling 2008), which presented an example design study (of a naval combatant) in some detail, since it was argued that such a detailed consideration of the steps in a early stage ship design had not been previously outlined. This assertion was justified by considerations of previous design expositions, which had either been of a generic form (see Watson \& Gilfillan (1977) and Eames \& Drummond (1977)) or where the initial phase, for a specific ship design, had only been described to a limited degree, as part of the description of its overall evolution to its eventual build (see Leopold \& Reuter (1978), Honnor \& Andrews (1981) and Bryson (1985)).

The next section of this paper considers further the various attempts there have been to model the ship design process (and particularly the initial phase) before the specific form of representation of the design process by a design spiral is discussed in Section 3. This leads on to further consideration of the non-linearity of a ship design, as it evolves into an eventually balanced design. The UCL architecturally based Design Building Block (DBB) approach (see Andrews \& Pawling 2006), used in this particular investigation of a specific set of naval combatant design studies, is then introduced followed by an outline of the studies undertaken in this investigation. The results of these studies are then outlined and discussed before consideration as to what insight these convey as to the nature of ship design evolution and the validity or otherwise of the ship design spiral to describe such a process. 


\section{MODELLING THE SHIP DESIGN PROCESS}

Such publications as the IMDC State of Art (SoA) Design Methodology Reports (Andrews et al 1997, Andrews et al 2006 and Andrews et al 2009) largely concentrated on the preliminary or initial/concept design phase, given its importance for the eventual design. Thus the initial SoA reports on design methodology (Andrews et al 1997) had a specific section on preliminary ship design. The 1997 SoA Design Methodology Report, as well as having sections on the design of some six ship types, in its sixth section briefly reviewed some twenty approaches to preliminary ship design. These included a representation of the full preliminary ship design process with continual feedback. A recent update (Andrews 2013) is reproduced at Figure 1. At the appendix is a short explanation of each box named in Figure 1. Figure 1 can be contrasted with Figure 2, which shows a simple numerical synthesis with a single fixed iterative loop necessary to achieve a purely numerical balance at the end of the sizing step, rather than the integrated synthesis identified in Figure 1 as the eighth step.

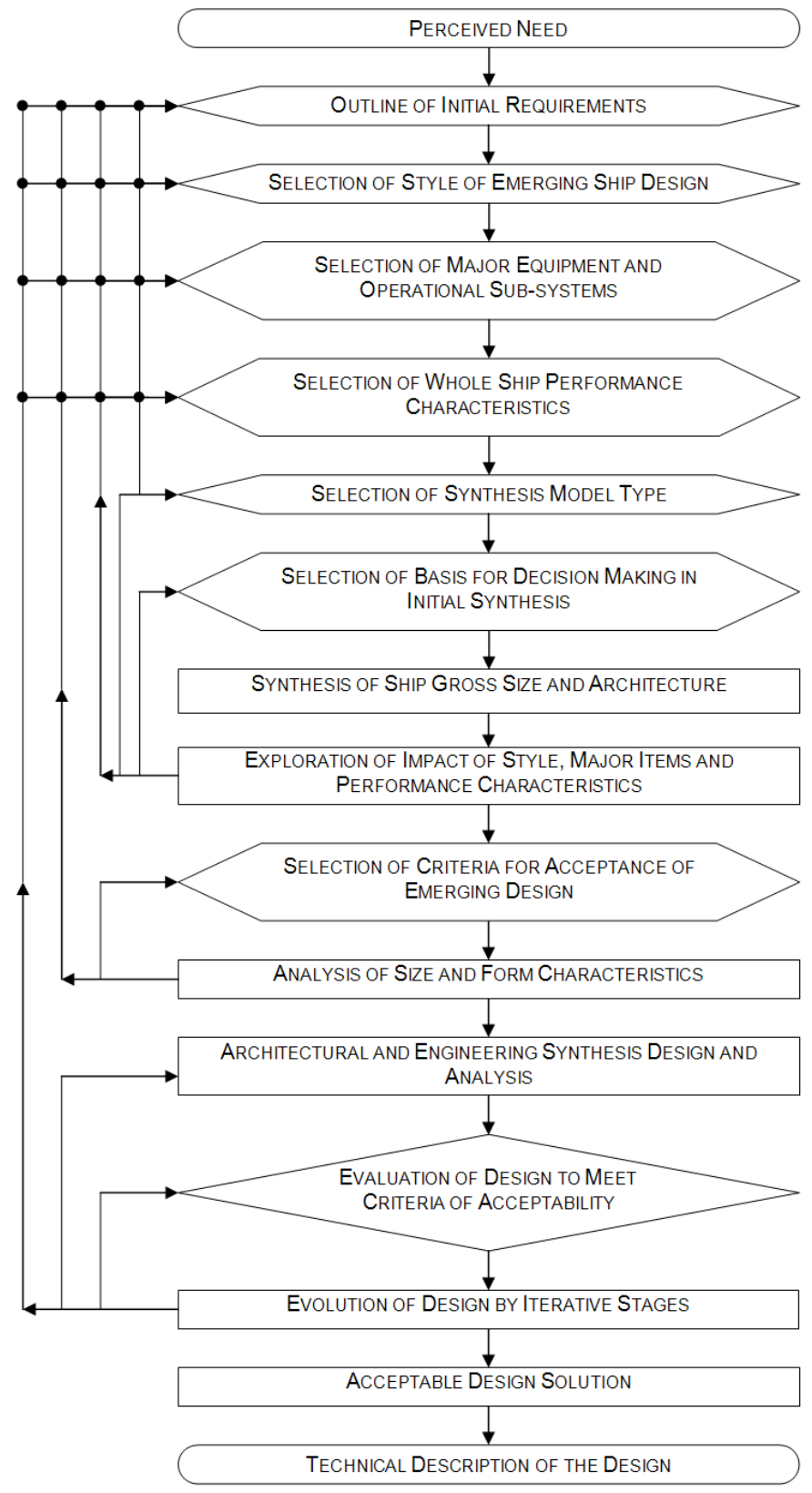

Figure 1 A representation of the full preliminary ship design process with continual feedback (Andrews 2012) 


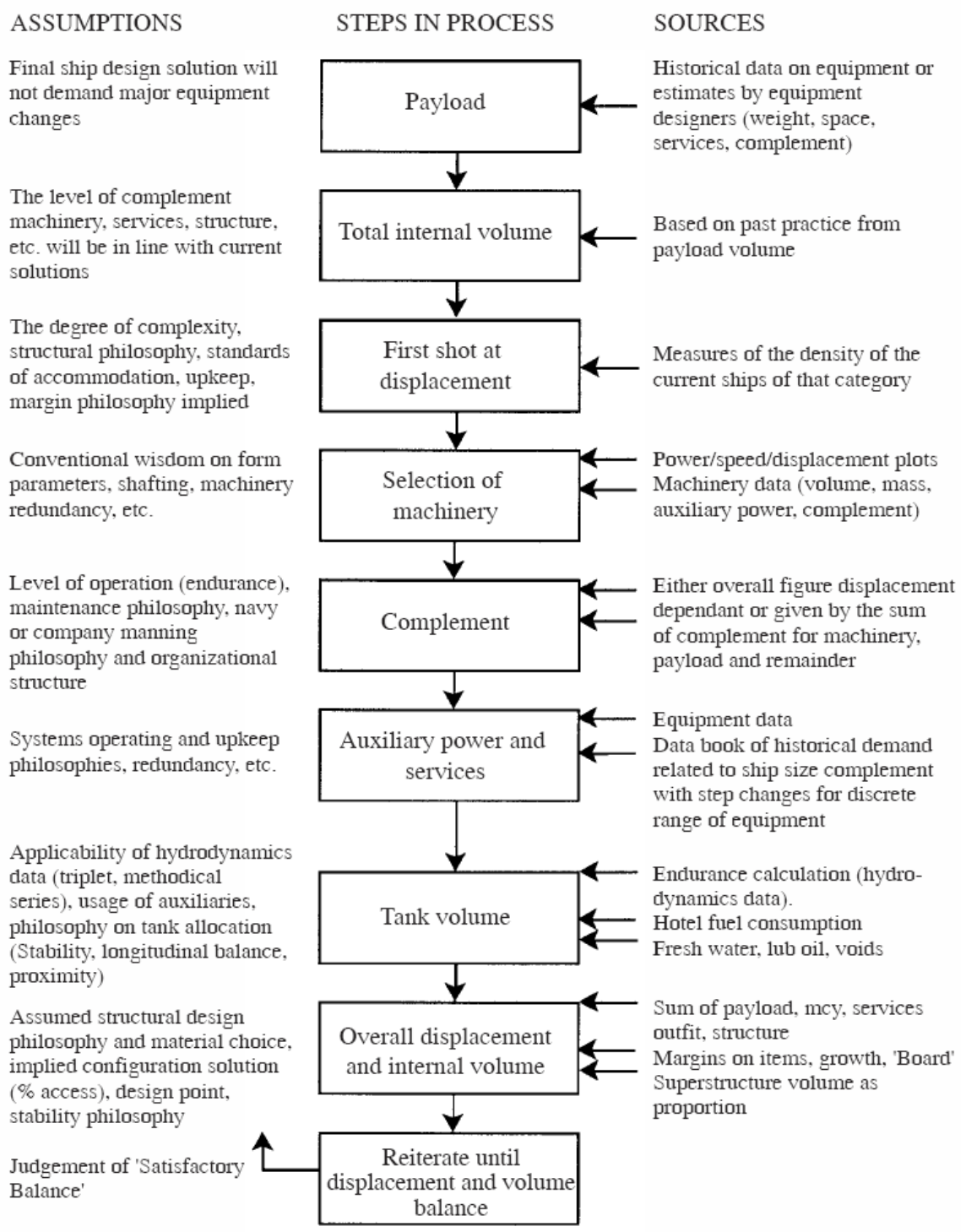

Figure 2 A Simple Numeric Ship Sizing Iterative Sequence with Feedback (Andrews et al 1997)

A second caveat is that using such synthesis or sizing approach to initial ship design also has an implicit assumption as to the degree of novelty being adopted for the ship solution. This was addressed by Andrews (1998) with examples of increasing design novelty, reproduced in Table 1, ranging from a simple stretched design for a follow-on batch or flight of an existing ship design, right through to a solution adopting a radical technology, where the design process needs to be more akin to the massive $R \& D$ projects at the cutting edge of aerospace, even when compared to the bulk of naval combatant acquisition. The most important feature of Figure 2, which in the steps shown is common to most initial ship design sizing methods and tools, is the addition of the assumptions and the sources of the "rules of thumb". These are implicit in any such numerical process but usually not even stated to be inherent in adopting such an approach and the associated sizing tool. Furthermore many introduce nonlinearities into the iterative balance of weight, space and naval architecture.
Table 1 Types of Ship Design in terms of Increasing Novelty (Andrews 1998)

\begin{tabular}{|c|c|}
\hline Type & Example \\
\hline second batch & RN Batch 2 Type 22 frigate \\
\hline simple type ship & many naval auxiliary vessels \\
\hline evolutionary design & a family of designs \\
\hline $\begin{array}{l}\text { simple numerical } \\
\text { synthesis }\end{array}$ & UCL student designs \\
\hline $\begin{array}{c}\text { architectural \& } \\
\text { numerical synthesis }\end{array}$ & UCL design studies \\
\hline radical configuration & SWATH, Trimaran \\
\hline radical technology & $\begin{array}{c}\text { US Navy 1970s Surface Effect } \\
\text { Ship (3KSES) }\end{array}$ \\
\hline
\end{tabular}


A further caveat is to list five features, stated by Andrews (2003), as seen to be necessary in any approach to initial ship design - to which we will return later in this paper but are appropriate to outline now, as they capture the sophistication implicit in a proper initial ship design process:-

- Believable solutions, meaning ones that are both technically balanced and descriptive; thus, initial ship design solutions will be more believable if crucial issues related to wider design issues (e.g. personnel movement) are investigated as part of initial ship design;

- Coherent solutions, meaning that the dialogue with the customer should be more than a focus on numerical measures of performance and cost, and should include visual representation; given the end customer is the ship user, greater coherence and due regard for ship operational aspects would be achieved;

- Open methods, in that they are responsive to the issues that matter to the customer or capable of being elucidated from the customer or user teams; here the elucidation process would be extended to respond to customer concerns many of which have not been addressable in "traditional concept design";

- Revelatory, so likely design drivers are identified early in the design process to aid effective design exploration; some design drivers more likely to be revealed through specific simulations and thus become addressable in initial ship design. Furthermore, the consequential impact on design viability and impact on cost and delivery of potential changes later in the ship design process could be ameliorated, if the ship designers could conduct such explorations earlier in the design process;

- Creative, in that options are not closed down by the design method and tool adopted but rather alternatives are fostered; through addressing wider issues, at the most malleable stage in design, providing more scope for innovative solutions to be considered.

The 2009 IMDC SoA Design Methodology Report presented some 27 iconographic representations of the ship design process. While these ranged across the whole of the ship design process and some are specific to particular ship types (such as MacCullum \& Duffy (1987) for deadweight carriers and Papanikalaou (2004) for Roro passenger ships), eight of these representations were versions of the ship design spiral, which is examined further in the next section. Before that, it is worth looking both at the wider consideration of the iterative nature of preliminary ship design and also the interactive characteristic that would appear to challenge any sequential and hierarchical representation of the process. This is seen to be particularly significant if, rather than adopting the numerical sizing process of Figure 2, the designer employs an architecturally based synthesis approach, such as the DBB approach referred to in the last paragraph of the Introduction. It is worth remarking that the term "an architectural description" is seen to have a wider meaning than just the physical representation of the ship's general arrangement or layout. Rather the overall configuration's architecture can be seen to include the organisation or structure of the design description (both iconic and numeric). The use of the term architecture in the organisational or structural sense is often adopted for software (see Maier 1996). However, this meaning of a design's structure is usually avoided by naval architects since it can be confused with the term, normally reserved in ship design for consideration of a ship's strength (i.e loading and structural response of the overall hull and the detailed "steelwork" design).

Many of the (largely iconographic) representations of the preliminary ship design process, such as those in the 2009 IMDC report, show the iterative nature of that process, which is seen as one of the advantages of the design spiral representation. This iterative characteristic even applies to most of the other, largely sequential, representations of the process. Thus Figure 3 reproduces a detailed outline of the submarine sizing procedure on three pages, starting with operational requirements and going through the process to achieve a balance in space \& weight and then cost and naval architectural analysis (Burcher \& Rydill 1994). This is achieved to a level appropriate to submarine concept design, with no less than eleven feedback loops. This feedback process can be seen in both the classical sequential ship design synthesis (Figure 2) and in the more integrated approach behind the DBB approach adopted in the investigation outlined in this paper. This paper therefore summarises the DBB approach for the purposes of this investigation, however it can be noted, from the twelfth preliminary ship design representation in the 2009 IMDC SoA design methodology report, that in both the numerical sequential and the architecturally integrated (DBB) representations the output is fed back to the input, once a ship design balance has been achieved. This reconsideration of the input (requirements) is entirely consistent with the preferred systems engineering approach of Requirements Elucidation propounded by the second author (Andrews 2012). So there is both feedback at a gross level of the whole ship design process, which is often seen to be consistent with achieving one revolution of the design spiral, but this is also seen to occur at each component step (such as the purely numerical balance of weight \& space of Figure 2). These are subtleties not easily modelled by a single design spiral. 


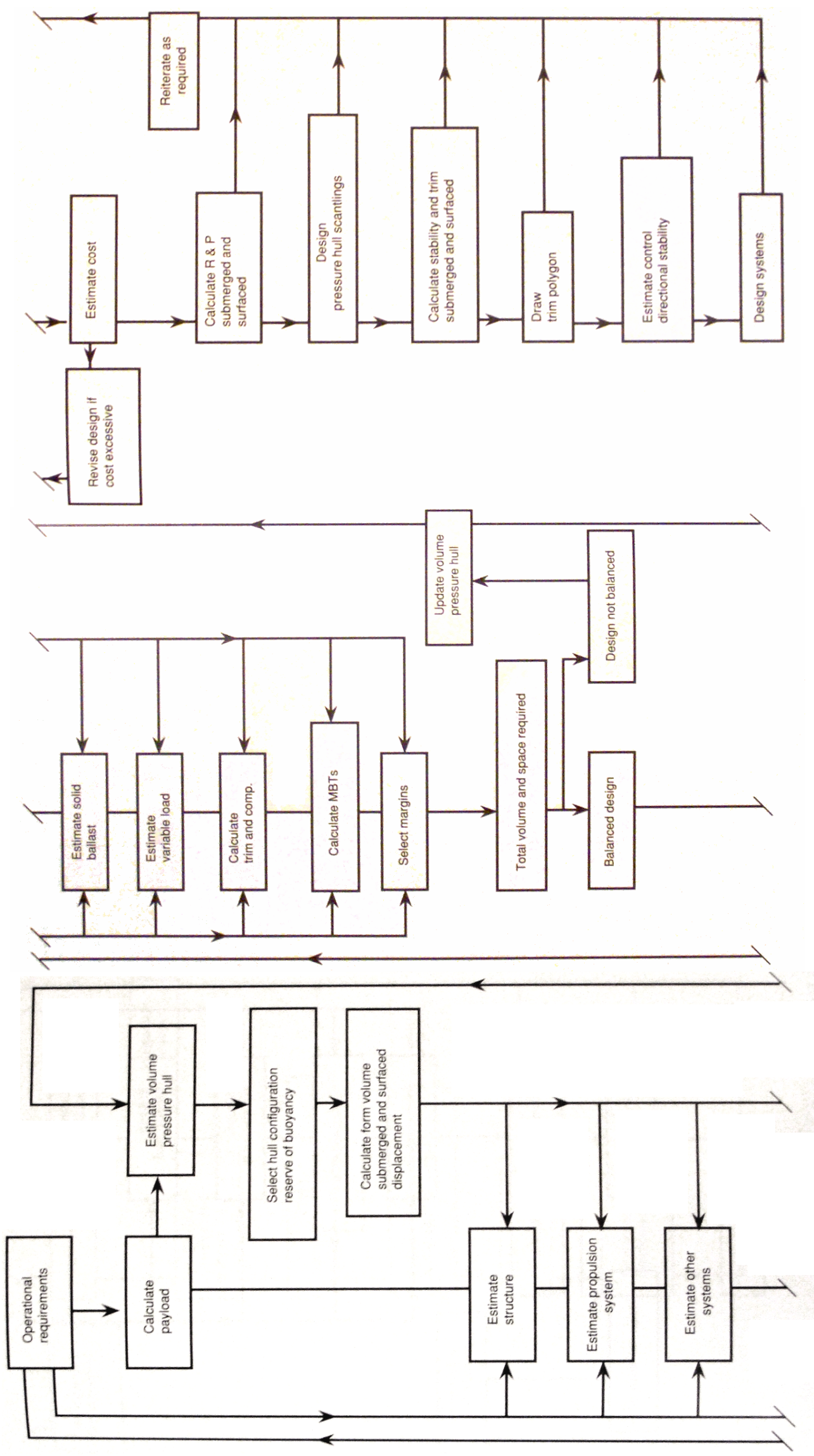

Figure 3 Detailed outline of the submarine sizing procedure (Burcher \& Rydill 1994) 
The other aspect that the design spiral is considered to model, or at least acknowledge, is the interactive nature of ship design. This is said to persist through out the process, such that any change in a sub component system has knock on effects across a range of other supporting ship systems. Thus simply in sizing fuel tanks on a naval ship, Rawson \& Tupper's classic text book (1976) shows what is called a "design influence diagram" to reveal the influence on both the preliminary sizing and the final fuel tank arrangements. So changes in anyone of the influences will lead to alterations in this set of fuel tanks. Thus there are a host of interacting consequences with most of the ship design variables being interdependent to a significant degree. The set of tanks will then themselves have influences on, typically, the stability of the ship requiring changes to ship dimensions, weight balance and structural scantlings, which will further alter the design downstream across a whole range of other component subsystems.

A second example of interaction was presented by Andrews (1996), when outlining trimaran research at UCL, which led, some four years later, to the first ocean going trimaran ship, R.V. TRITON. To show how typical design issues can be interrelated, the example was given of the size and athwartships separation of the side hulls, which might lead to resonance in ship roll response at a frequency likely to be experienced at sea. This could then require the configuration of the side hulls to be changed. Such a change could then alter the ship's resistance, so to maintain the required speed bigger engines could be required, driving up the ship's size. The change to side hull separation would then alter the vessel's stability requiring further side hull changes, altering the ship's manoeuvrability requiring bigger rudders and possibly weakening the ship's structural strength. This would require more strengthening again increasing the ship's weight, its displacement, its resistance, its engines, the fuel carried, all leading to further sequential increases until an adequate space and weight balance is finally restored (see Figure 4).

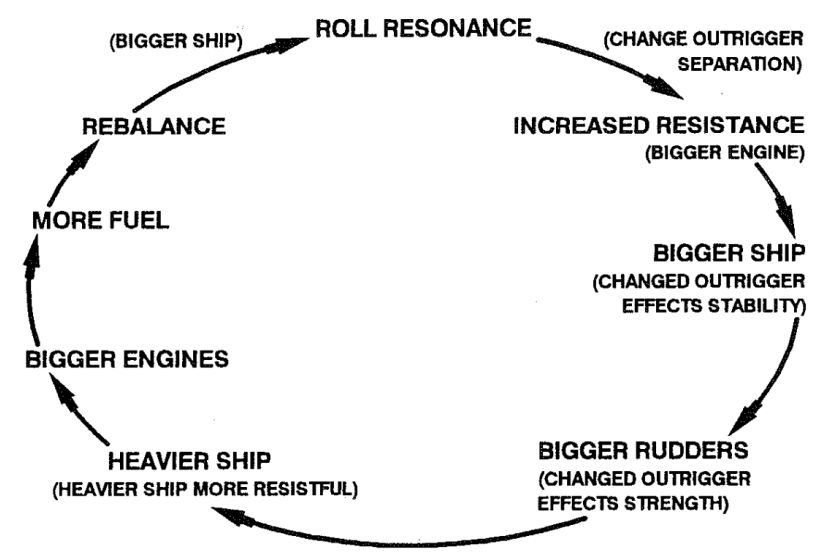

Figure 4 An Example of a Typical Design Sequence for Trimaran side hull design (Andrews 1996)
Thus these two aspects of ship design, the iterative and the interactive, need to be reflected in any model or representation of initial ship design, such as the design spiral, if it is to be a valid representation of the ship design process. In particular, such representations should indicate how a design evolves due to major changes in requirements or choices in design style in order to achieve a balanced design. The origins and critiques of the design spiral are next considered.

\section{THE DESIGN SPIRAL}

The first use of the design spiral in ship design is usually attributed to Harvey Evans (1959) in outlining the sequence for midship structural section design. His spiral has nine steps that were shown to be repeated several times - hence the spiral representation. This example was followed by several versions representing the whole ship design process (such as the second, third and ninth examples reproduced in the 2009 IMDC SoA design methodology report (Andrews et al 2009)). These show the same steps being undertaken at each sweep of the spiral (but clearly each time more comprehensively). Rawson \& Tupper (1973) even remark that not all the twelve steps, which they show, "are required to be developed in depth at every iteration".

Perhaps the most comprehensive representation of the ship design spiral is that reproduced at Figure 5, due to Rawson (1986). This has 27 steps round the spiral, since it includes the set of "prime' and "additional" hull form parameters, that he considers to be determined in the process. Furthermore this spiral reverses the usual spiralling inwards to a solution by spiralling outwards, perhaps suggesting the increase in complexity of the solution as it evolves but still (hopefully) converges? Each sweep is said to be a major phase of the whole ship design process, namely economics, military effectiveness (these cover commercial and naval vessels respectively), concept, feasibility and finally full design.

It is considered debatable whether each of the above major design phases should be shown as only one sweep. Eames \& Drummond (1977) (the fifth example in the 2009 SoA design methodology report) in their concept exploration paper show three concept stages, each as a complete sweep (called "concept exploration, concept development and concept validation") and with ten steps or "spokes". These follow the same sequence for each of their concept stages and the process starts with a "basis ship" (rather than even outline requirements) and ends with "contract design". The latter suggest this is modelling a process typical of a commercial shipyard's bid response to a ship owner's indicative design, rather than the more protracted concept phase for naval procurement. An example of the latter was outlined for UK warship procurement (Andrews 1994) with three overlapping stages entitled concept exploration (but quite different to the Eames \& Drummond 1977 usage, being much more divergent), concept studies and concept design, all undertaken prior to what is now known as the Initial Gate decision point in the UK Ministry of Defence (UK MoD 1999). It is also relevant that each of these concept stages do not follow the simple repetitive description of the design spiral, as the 1994 paper demonstrates. 


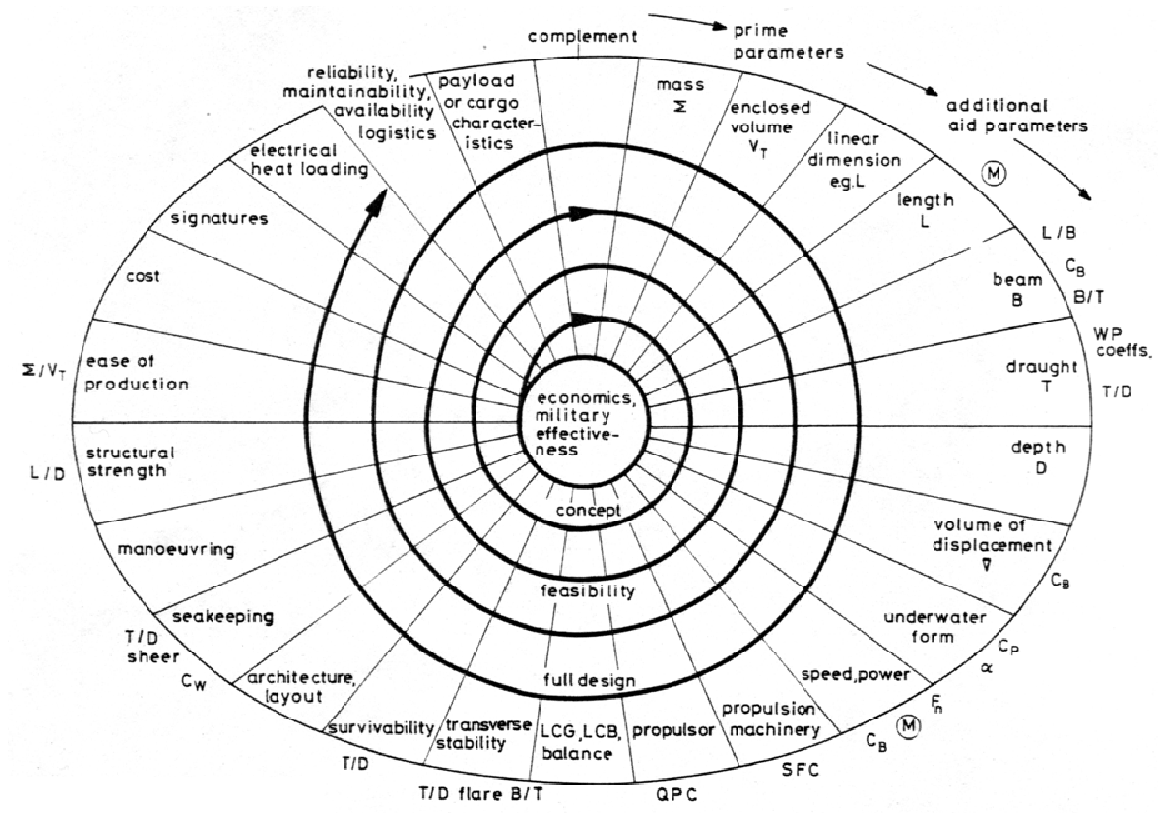

Figure 5 A ship design process model (Rawson 1986)

A further variant on the representation of the design spiral was proposed in 1981 by Andrews (see Figure 6, the sixth example in the 2009 IMDC SoA design methodology report). This gives a three dimensional picture of the design spiral, as a tapering corkscrew, for each of the major ship design phases. It was done to emphasise, unlike the two dimensional representation with a progressive sequence of closed loops, that real ship design operates with considerable dialogue in and out of the looping process with inputs by the designer and the many stakeholders.

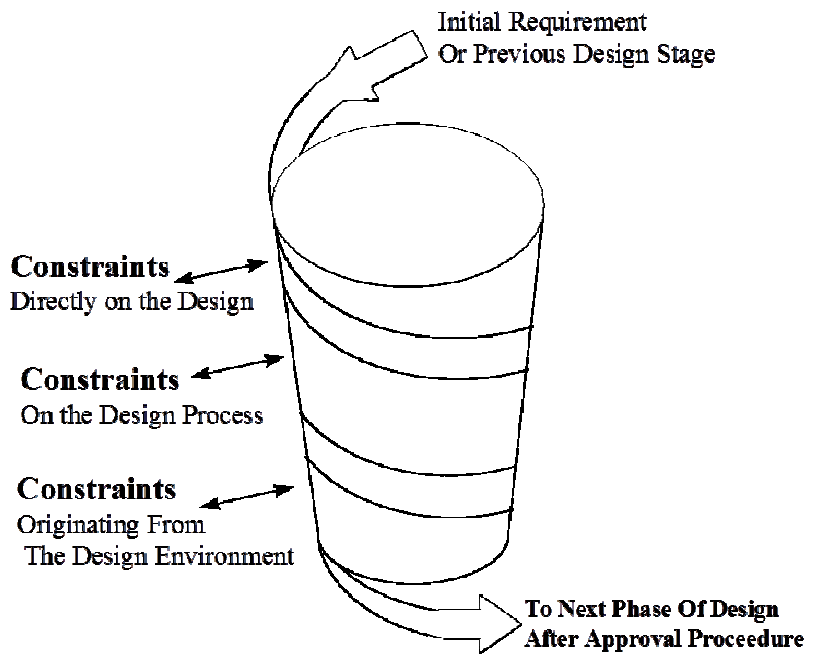

Figure 6 3-D Representation of the Ship Design Spiral (Andrews 1981)

Thus strong interactions are suggested throughout the spiralling process with a series of external influences or constraints. These constraints were described as respectively:-
- Directly on the design - seen as direct impositions from the customer/users/ specialists/classification societies, for aspects such as reduced manning;

- On the design process - such as sources of design data and tools/methods/standards, which might well alter the spiral sequence and lead to the process jumping back and forth, also some of these can be influenced by the design team;

- Originating from the design environment - these are wider constraints, such as the education and training of the designers, government legislation (e.g. environmental/safety), economic climate, major organisational changes, all of which can be highly influential but over which the design team has no influence.

This 3-D model was intended to describe (any) one phase of the ship design process and as such could require several complete spirals to achieve the appropriate design balance. This model was felt to be consistent with the description of the concept phase and also with the subsequent feasibility phase undertaken after the concept phase and prior to approval to contract for detailed design and construction. The second author has managed projects with year long feasibility studies, which were only considered to be complete after three full cycles of design balance, each of increasing design fidelity.

Having remarked that the design spiral takes many forms in trying to represent a complex process, it is now appropriate to consider non-linearity in the evolution of most ship designs and whether this fact limits the value of the design spiral in modelling the design process. 


\section{THE NON-LINEARITY OF SHIP DESIGN EVOLUTION}

A direct criticism of the design spiral was stated by the experienced UK naval ship designer and writer on ship design, David Brown (Brown 1986):-

"The naval architectural aspects of the design are also difficult to structure and are not properly represented by flow diagrams such as the design spiral. This process too involves closed loops and intuitive leaps while performance functions are nonlinear and often discontinuous, and inequalities are often more common than equations."

This looping, nonlinear and discontinuous nature presents problems not just in using the design spiral to attempt to represent the ship design process, but also for many of the computer based systems ubiquitously used to achieve balanced solutions through rapid iterating. Such "black box" concept methods are also used to explore the effect of changes in requirements be they in payload demands or ship performance, such as speed and endurance (see step 9 in Figure 1; step 4 in Figure 2; and Garzke \& Kerr 1985). But if the process actually has Brown's characteristics then this suggests the "regular" process of the design spiral and the use of algorithms with continuous variables might be seriously misleading.

Such a realisation (together with a belief in the need to incorporate the architectural facet alongside the numeric) led the second author to propose a much more interactive design approach in the Design Building Block technique to the design of Physically Large and Complex systems, typified by the modern naval combatant (Andrews 1981, $2003,2012)$. This requires the design tool to inform the designer in what respect the design is unbalanced but leaves the designer to make the changes to achieve the balance both numerically and architecturally. It then enables the designer to decide whether the current algorithm(s) or performance assessment method is still appropriate. Thus the discontinuous nature of the process and the scope for intuitive leaps can be exploited. As can be seen from Figure 1 the approach allows for many loops and interventions by the designer in the overall early stage design process. However the iterative nature can still be represented by a version of the spiral, or at least as a nominally closed loop, in the architecturally led sequence of the SURFCON realisation of the DBB approach, as is shown in Figure 7. The one proviso is that the various sub-steps shown in this figure allow for several paths and different degrees of input to the space, geometry, weight and balance steps. The choice is dependent on the appropriate level of definition the particular design study is at. This level varies between that sufficient for an initial major feature definition level and the full (building block based) general arrangement likely to be produced at the end of concept design (Andrews \& Pawling 2008).

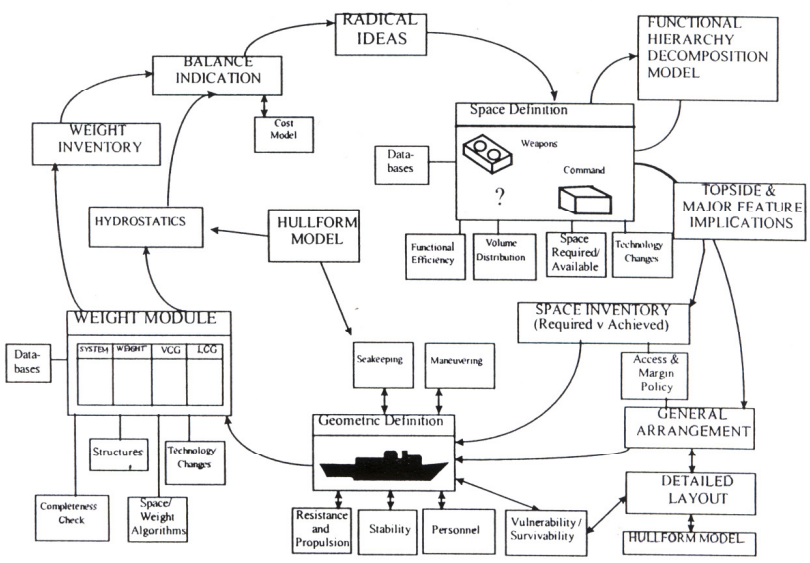

Figure 7 Building Block Design Methodology Applied to Surface Ships (Andrews \& Dicks 1997)

An early example of investigating the behaviour of a ship design, as various input parameters are varied, was carried out by Andrews \& Brown (1982) in looking at how to reduce the cost of a typical frigate design of the time. The measures applied are given in Table 2 and a plot of Deep Displacement reduction against Unit Procurement Cost (UPC), at 1982 levels, is shown at Figure 8. If cost is taken as the most significant design output then it is noticeable that this has a far from linear relationship with overall displacement, belying the (politically attractive) simplicity that ship size is directly proportional to cost. In fact as Figure 8 reveals certain features (such as the adoption of "cellularity" for electronic systems (Gates 1986) and better design for production installation (Andrews et al 2005)) can reduce UPC through the adoption of a larger ship size. The study summarised in Figure 8 study was undertaken before the UCL DBB approach was fully incorporated into the GRC Paramarine software suite (Munoz \& Forrest 2002) and so only deals with spatial demands at a gross level, rather than the specific space demands of the individual design building blocks used in the current investigation. 
Table 2 Specific Examples of Major Steps in Frigate UPC Reduction (Andrews \& Brown 1982)

\begin{tabular}{l|l|c|c}
\hline \multicolumn{1}{c|}{ Measure } & \multicolumn{1}{c|}{ Specifics } & $\begin{array}{c}\text { Reduction in UPC, } \\
\mathbf{E M}(\mathbf{\$ M})\end{array}$ & $\begin{array}{c}\text { Reduction in Deep } \\
\text { Displacement, tonnes }\end{array}$ \\
\hline $\begin{array}{l}\text { Role } \\
\text { Definition }\end{array}$ & All round PDMS reduced to single (fwd) system & & 300 \\
C3 reduced to private ship from group command & $26(50)$ & \\
Complement & Helicopter reduced to very limited maintenance & $5(10)$ & 600 \\
Cellularity & Improved layout for reduced complement & $3(6)$ & -300 \\
Production & Reduced installation times & $3(6)$ & -200 \\
NBCD & Ship systems configured to avoid conflicts & $1(2)$ & 200 \\
Margins & Omission of biological and chemical citadel & $2(4)$ & 500 \\
\hline & Short life ship with a growth margin of 5 years & $40(80)$ & 1100 \\
\hline
\end{tabular}

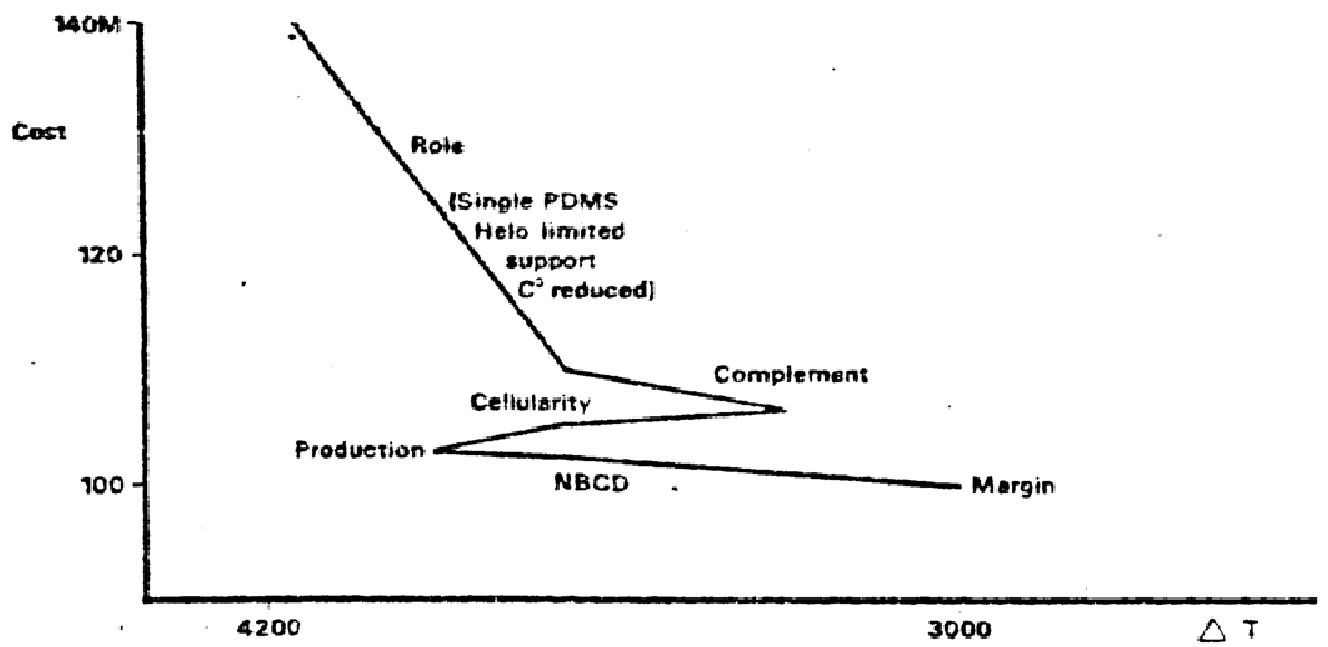

Figure 8 Cost Conscious Ship Design: financially driven capability reduction (Andrews \& Brown 1982)

A more recent investigation using Paramarine with the SURFCON DBB module was undertaken by Peron (2002). This investigated considered whether the linear plateau followed by step (or cliff) effects in size and cost growth occurs due to changes in "payload" (i.e. combat systems features for a naval combatant). Peron's conclusions were inconclusive due to:

i. the explicit payload changes having small demands on overall ship size despite, often, significant impacts on UPC;

ii. despite the use of the SURFCON DBB tool to produce architectural impacts of the combat system changes, Peron failed to also investigate the consequential changes to the hull form (and hence displacement) to accommodate the spatial differences if the same performance requirements are to be met as in the baseline design.

It was therefore decided that the 2010 investigation would not only deal with the second of the above issues, by fully exploiting the SURFCON-Paramarine facility, but also explore items of naval combatant design, which have been seen to be more significant in affecting ship sizing than changes to combat system features. These other items conveniently come under the heading of "Style" in the " $\mathrm{S}$ "" set of ship design aspects, namely speed, seakeeping, stability and strength, alongside style (Brown \& Andrews 1981). The various style aspects often have the consequence of significantly affecting the architectural characterisitics of the ship design. Thus amongst the style issues, comprehensively listed by Andrews (2012), those of margins (e.g. for design evolution and Through Life adaptability), survivability (e.g. zoning), main access philosophy (passageways and stair wells) were considered to be of particular interest in this investigation. Altering design margins was of particular interest as it allowed the investigation of the effect of a linear increase in a numerical parameter on a design developed using an architectural approach.

\section{THE USE OF THE DESIGN BUILDING BLOCK TO EXPLORE CONCEPT EVOLUTION}


The UCL Design Building Block architecturally driven design approach has been outlined previously (Andrews \& Dicks 1997, Andrews \& Pawling 2003, 2006, 2009) and most comprehensively in a preliminary ship design study of a trimaran combatant (Andrews \& Pawling 2008). It is also iconically summarised in Figure 7 above. The other feature of the DBB approach is to design using a "functional" taxonomy of "Float, Move, Fight and Infrastructure" (see Andrews \& Dicks (1997) for detailed description). In the second author's investigation (Percival 2010) the approach to setting up the Reference Design to study the nature of growth in a naval combatant design was based on steps spelt out in the 2008 trimaran study.
Table 3 shows how far the "Reference Design" proceeded down the DBB design stages and also the steps and levels of granularity at which the two variants investigated stopped. This limitation was partly driven by time but also by a belief that the characteristics being investigated could be revealed to a sufficient level of design granularity that conclusions on the nature of design evolution could be discerned.

Table 4 gives the primary combat and ship performance requirements for the proposed "versatile escort vessel with an intermediate task group defence capability".

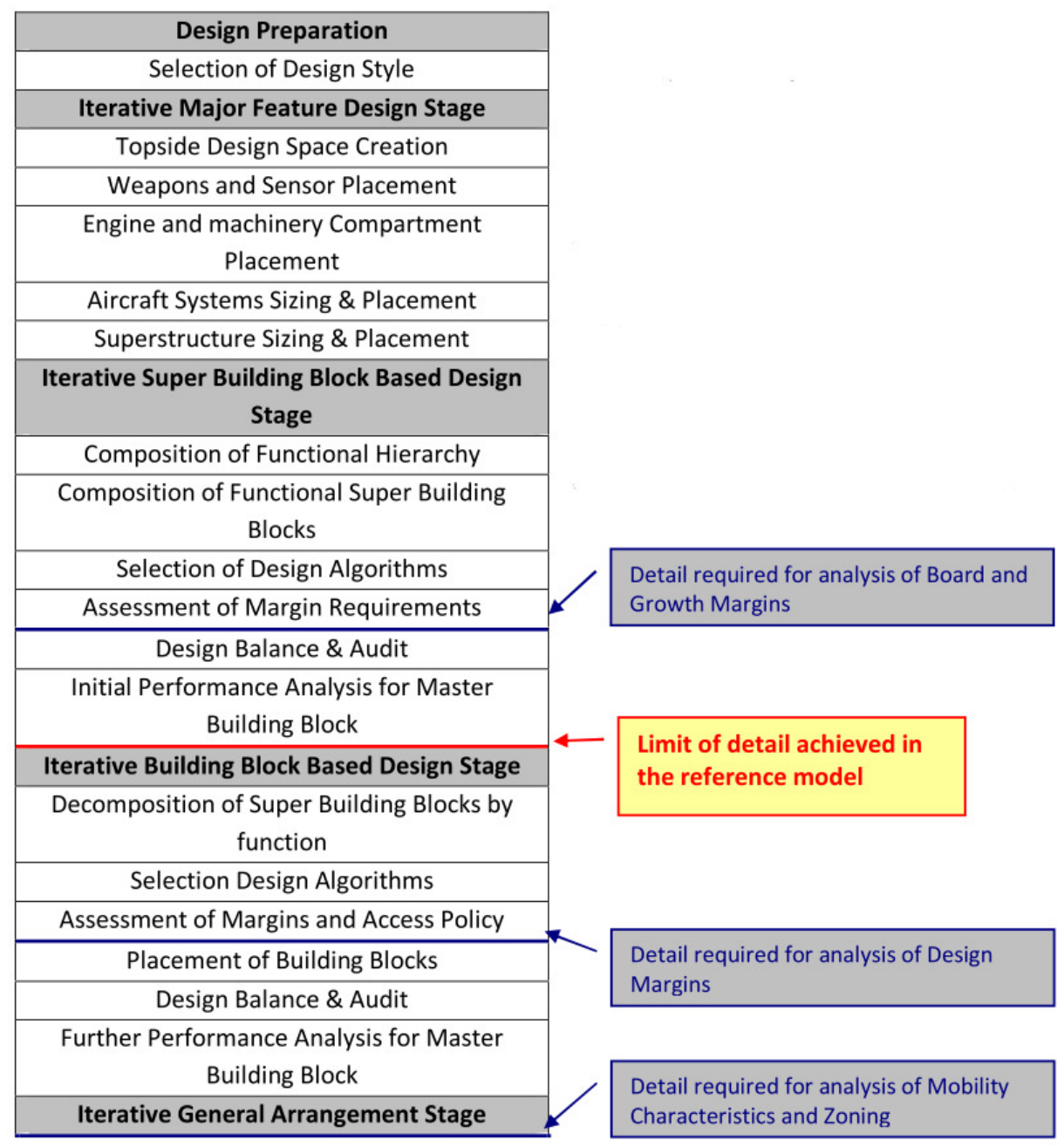

Table 3 Comparison of Reference frigate investigated by Percival (2010) against the Typical Design Stages for a Surface Ship Building Block Design (Dicks, 1999) 
Table 4 Primary combat system and ship performance requirements (Percival 2010)

\begin{tabular}{l}
\hline Payload \\
\hline - FLAADS(M)/CAAM(M) AAW missile system \\
- Hangared Lynx Helicopter (fitted with Stingray ASW \\
torpedo and Sea Skua ASuW missile) \\
- 1 Hangared Firescout UAV \\
- Otbobreda 127 mm Naval Gun \\
- DS30B Canons \\
- seaRAM CIWS \\
\hline Ship Characteristics \\
\hline - Operating Profile: 28 kts Top / 15 kts passage speed \\
- Range: 6000 nautical mile fuel endurance at passage \\
speed \\
- Endurance: 30 days stores endurance \\
- Complement: Routine Complement of 182. \\
- UXV Deployment: Provision for UXV forward \\
deployment by means of versatile workshop space and \\
weather deck deployment area. \\
\hline
\end{tabular}

Table 5 shows the five types of spaces adopted in the investigation at the Super Building Block level (see Table 3 ) in a sequence reflecting that of a conventional combatant. Figure 9 shows the compartment disposition for the reference design in progress, in a manner similar to that of the UCL 2008 trimaran study, albeit for a more conventional monohull. Space in this article precludes presentation of the full process of the design study and the details of the weight and space balance achieved. Thus such aspects as the selection of the scheme of complement (comprising 182 personnel including margins) and the assessment of the " $\mathrm{S}$ " set of ship design aspects have been omitted here. All these elements go to providing a valid design on which to conduct investigations that can be considered reasonably realistic in exploring the initial ship design process. These details are contained in Percival's (2010) study report. Figure 10 shows the reference design (the Multirole Reference Frigate) and a distinct "stylistic variant" with reduced superstructure (Minimal Superstructure Frigate). These designs had the following Deep Displacements and Gross Enclosed Volumes (2990 tonnes and 3500 tonnes, 11,800m3 and $15,000 \mathrm{~m} 3$ respectively).

Table 5 Super Building Block Contents listed by internal adjacency requirements and spatial demands (Percival 2010)

\begin{tabular}{|c|c|c|}
\hline \multicolumn{3}{|c|}{ Level 1 External Demand Spaces } \\
\hline SBB No & SBB Title & DBB Components \\
\hline 1.1 & Bridge \& Wings & Bridge, Chart House \& Compass Room \\
\hline 1.2 & Steering Position & Steering Gear, SSP \\
\hline 1.3 & MMS & All MMS, Uptakes, RU Fuel Tanks, Lub Oil Tanks \\
\hline 1.4 & Sonar & Sonar Instrument Room \\
\hline 1.5 & Radar & Radar Equipment \\
\hline 1.6 .1 & Major Weapon Payload: AAW & CAAMS $4 *$ Quad packs \\
\hline 1.6.2.1 & Major Weapon Payload: ASuW 30mm & $2 * 30 \mathrm{~mm}$ canon $\&$ mountings \\
\hline 1.6.2.2 & Major Weapon Payload: ASuW $127 \mathrm{~mm}$ & $1 * 127 \mathrm{~mm}$ gun \& Directly linked Gunbay \\
\hline 1.6 .3 & Major Weapon Payload: cIws & $2 *$ SeaRAM \\
\hline 1.7 & Hangar & $\begin{array}{l}\text { Flight Deck, Hangar, Air Weapons Mag, Aviation } \\
\text { Stores \& SE }\end{array}$ \\
\hline 1.8 & Boat Bay & Boat Bay, Davits, Boat Store \\
\hline 1.9 & Cargo Store & Ready Use Solid \& Liquid Cargo Stores \\
\hline \multicolumn{3}{|c|}{ Level 1 External Demand Spaces } \\
\hline SBB No & SBB Title & DBB Components \\
\hline 1.1 & Bridge \& Wings & Bridge, Chart House \& Compass Room \\
\hline 1.2 & Steering Position & Steering Gear, SSP \\
\hline 1.3 & MMS & All MMS, Uptakes, RU Fuel Tanks, Lub Oil Tanks \\
\hline 1.4 & Sonar & Sonar Instrument Room \\
\hline 1.5 & Radar & Radar Equipment \\
\hline 1.6 .1 & Major Weapon Payload: AAW & CAAMS $4 *$ Quad packs \\
\hline 1.6.2.1 & Major Weapon Payload: ASuW 30mm & $2 * 30 \mathrm{~mm}$ canon \& mountings \\
\hline 1.6.2.2 & Major Weapon Payload: ASuW $127 \mathrm{~mm}$ & $1^{*} 127 \mathrm{~mm}$ gun \& Directly linked Gunbay \\
\hline 1.6 .3 & Major Weapon Payload: cIws & 2* SeaRAM \\
\hline 1.7 & Hangar & $\begin{array}{l}\text { Flight Deck, Hangar, Air Weapons Mag, Aviation } \\
\text { Stores \& SE }\end{array}$ \\
\hline 1.8 & Boat Bay & Boat Bay, Davits, Boat Store \\
\hline 1.9 & Cargo Store & Ready Use Solid \& Liquid Cargo Stores \\
\hline
\end{tabular}




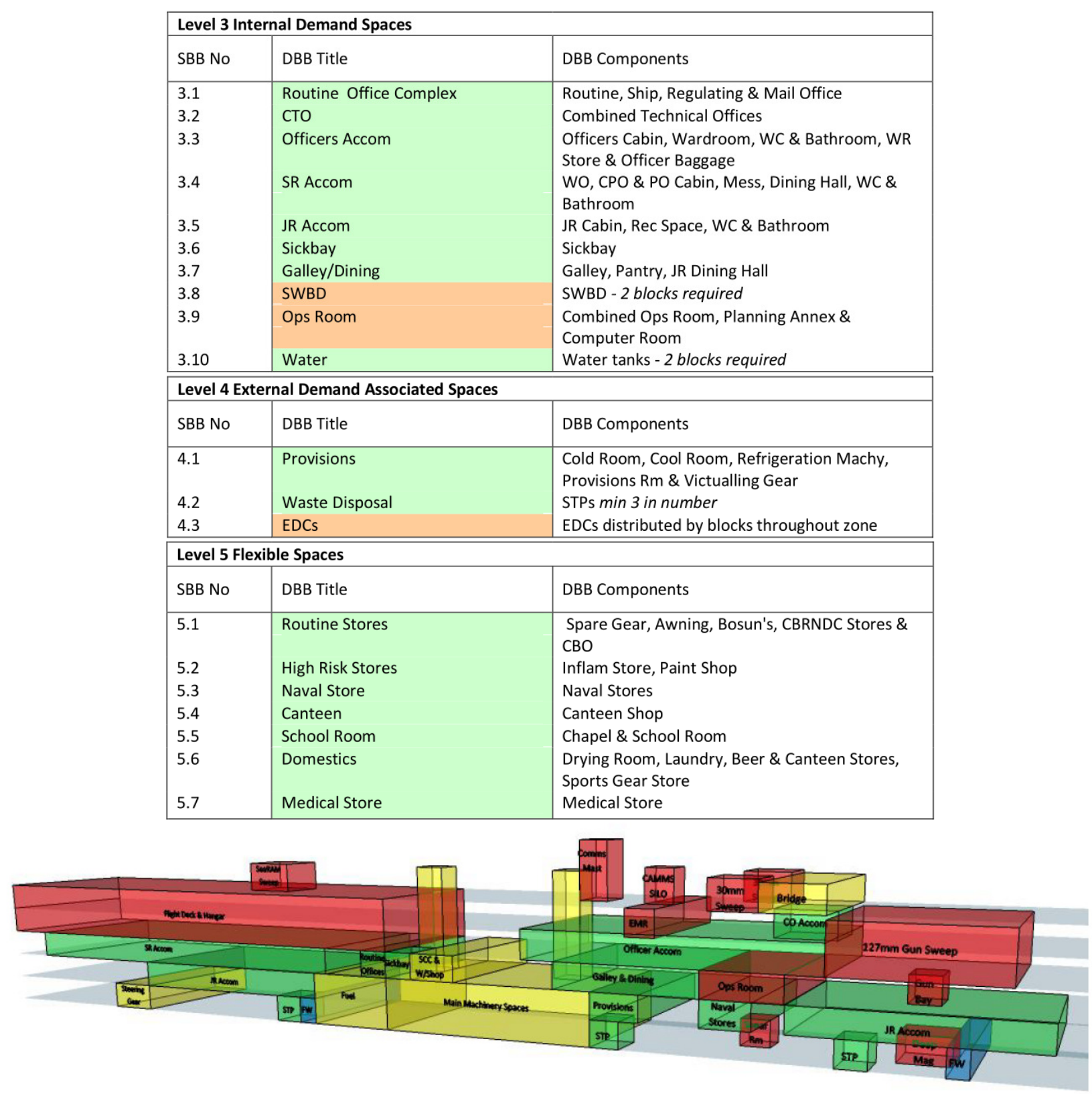

Figure 9 Early compartment disposition for the reference design used in the study (Percival 2010)

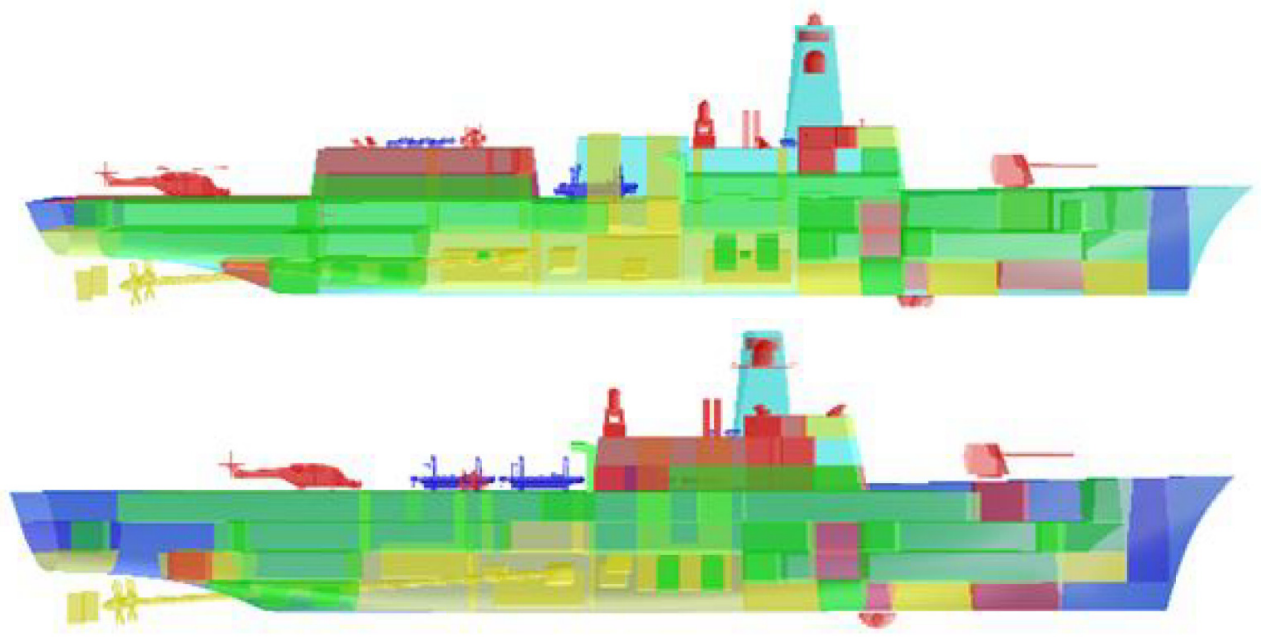

Figure 10 Elevations of DBB Models for Multi-Role.v1 Frigate (top) \& Minimal SS Frigate (bottom) (Percival 2010) 
As indicated by Table 3 the variants explored were those associated with varying the margins for both of the baseline designs. Although combined Growth (e.g unplanned annual growth in weight and rise in $\mathrm{KG}$ ) and Board Margins (UK term for provision for future capability enhancements) for just weight (as is currently applied in UK practice (MoD 2000)) were investigated as well as Board Margins (for weight and space), however only the latter margins are discussed in detail in the next section. In these variants certain design limits and assumptions were imposed on the variants to avoid unrealistic designs. These are summarised in Tables 6 and 7.

Table 6 Design Limits used in Investigations (Percival 2010)

\begin{tabular}{|c|c|}
\hline Design Limit & Justification \\
\hline Circ $M<8$ & To avoid narrow 'difficult to manufacture' compartments at the extremes of length. \\
\hline $\mathrm{L} / \mathrm{D}<12$ & $\begin{array}{l}\text { To maintain structural strength of the hull girder without significant structural weight } \\
\text { and hence cost impact. }\end{array}$ \\
\hline $\mathrm{B} / \mathrm{T}<4$ & To achieve reasonable transverse stability and natural roll periods. \\
\hline $\mathrm{T} / \mathrm{D} \sim 0.5$ & To provide a relatively dry deck for the given freeboard. \\
\hline $2.7<\mathrm{DH}<2.9 \mathrm{~m}$ on passing decks & To maintain necessary clearance for system runs overhead. \\
\hline $\begin{array}{l}2.0<\mathrm{DH}<2.5 \mathrm{~m} \text { on Non-Passing } \\
\text { (lower) decks. }\end{array}$ & $\begin{array}{l}\text { This was deemed acceptable due to reduced overhead system runs in these areas, } \\
\text { combined with the propensity of double height compartments (such as MMS) in this } \\
\text { area. }\end{array}$ \\
\hline $0.4<\mathrm{DB}<1.75 \mathrm{~m}$ & $\begin{array}{l}\text { To maintain realistic double bottom values that allow for manufacturing at the lower } \\
\text { limit and do not compromise weight distribution significantly, or waste space at the } \\
\text { upper limit. }\end{array}$ \\
\hline
\end{tabular}

Table 7 Modelling Assumptions used in Investigations (Percival 2010)

\begin{tabular}{|c|c|}
\hline Assumption & Justification \\
\hline $\begin{array}{l}\text { Access demands are fully accommodated within the } \\
\text { remaining available ship volume following DBB } \\
\text { disposition. }\end{array}$ & $\begin{array}{l}\text { Access is by its nature flexible and therefore should be configurable } \\
\text { within the realms of a practical GA. }\end{array}$ \\
\hline $\begin{array}{l}\text { Distributed Service Demands such as (Power } \\
\text { Distribution, SW ringmain and HP air) will not } \\
\text { conflict with the demands of the General } \\
\text { Arrangement }\end{array}$ & $\begin{array}{l}\text { Realistically critical service systems will be routed in the most direct } \\
\text { route, afforded suitable protection and redundancy. All of which can } \\
\text { be managed by sensible placement away from high risk } \\
\text { compartments. Any conflicts should be ironed out during later design } \\
\text { stages. }\end{array}$ \\
\hline $\begin{array}{l}\text { Void space can be allocated to satisfy all remaining } \\
\text { fuel and undefined volume demands. }\end{array}$ & $\begin{array}{l}\text { Enables simple volume balancing, and provides an illustration of the } \\
\text { required value of void space remaining }\end{array}$ \\
\hline $\begin{array}{l}\text { The inequality of value between all remaining } \\
\text { volume components is marginal. }\end{array}$ & $\begin{array}{l}\text { For this level of design, quantifying the values of remaining available } \\
\text { volume components would prove unjustifiably time consuming. }\end{array}$ \\
\hline $\begin{array}{l}\text { The design point shall be arbitrarily fixed } \\
\text { throughout the investigation. The mid life } \\
\text { ( } 10 \text { year) upkeep point has been chosen as this is } \\
\text { when a significant enhancement of payload and } \\
\text { equipment is likely. }\end{array}$ & $\begin{array}{l}\text { The additional complexity introduced by considering the various } \\
\text { demands of the future against the ship's capability will introduce an } \\
\text { unhelpful level of complexity when considering Board Margin. }\end{array}$ \\
\hline $\begin{array}{l}\text { The structural weight factor shall be assumed } \\
\text { constant across all variants. }\end{array}$ & $\begin{array}{l}\text { Arguably structural weight factors can be reduced for shorter hull } \\
\text { forms. However the influence of this factor is in itself an area for } \\
\text { separate investigation. As such it is deemed unwise to introduce this } \\
\text { unknown influence into the model. }\end{array}$ \\
\hline
\end{tabular}




\section{OUTCOME OF A DBB INVESTIGATION INTO DESIGN EVOLUTION}

\section{Variation of Board Margin for Multi-Role Frigate}

Eleven variants of the Multi-Role reference ship were produced, for incremental variations of Board Margin, applying both weight and space margin elements. The Board Margins under consideration ranged from no allowance to provision for a $100 \%$ increase in Fight demands. A 10:1 ratio was used to incorporate possible Infrastructure impacts as a result of the Fight enhancement. Key ship particulars for these results are provided in Table 8, with more detailed results in Percival
(2010). Notable features of the above results are highlighted in Figure 11. Of particular interest is the initial ship size growth in response to Board Margin variation, which appears to be linear. This behaviour is perhaps to be expected, given the first order application of weight and space demands required to provide the level of Board Margin. No significant alterations occurred to the architecture of the design, which is seen as the justification for the linear profile in ship size and thus shows no step or "cliff" effect. This is perhaps to be expected since the margin levels are relatively small and only applied to Fight and Infrastructure components of the whole ship. (Incidentally this seems to indicate the relatively small impact the Fight elements have on overall ship size.)

Table 8 Results for Board Margin variation for Multi-Role Frigate (Percival 2010)

\begin{tabular}{|c|c|c|c|c|c|c|c|}
\hline \multicolumn{8}{|c|}{ Multi Role Frigate } \\
\hline $\begin{array}{c}\text { FIGHT Margin } \\
\text { Value }(\%)\end{array}$ & $\begin{array}{c}\text { INFRA } \\
\text { Margin } \\
\text { Value (\%) } \\
\end{array}$ & $\Delta($ te $)$ & $\begin{array}{c}\text { Weight } \\
\text { Balance } \\
\text { Achieved (\%) }\end{array}$ & LWL (m) & $\begin{array}{c}\text { Volume } \\
\text { Balance } \\
\text { Achieved (\%) } \\
\end{array}$ & $\begin{array}{c}\text { No. } \\
\text { Passing } \\
\text { Decks }\end{array}$ & $\begin{array}{c}\text { Max } \\
\text { Range } \\
(\mathbf{n m}) \\
\end{array}$ \\
\hline 0 & 0 & 2855.01 & 1.55 & 106.08 & 5.77 & 1 & 4828.5 \\
\hline 5 & 0.5 & 2863.58 & 1.43 & 106.14 & 5.55 & 1 & 4727.5 \\
\hline 10 & 1 & 2872.60 & 1.29 & 106.20 & 5.15 & 1 & 4631.4 \\
\hline 20 & 2 & 2882.60 & 0.94 & 106.20 & 4.86 & 1 & 4414.1 \\
\hline 30 & 3 & 2892.57 & 0.60 & 106.20 & 4.01 & 1 & 4414.1 \\
\hline 50 & 5 & 2912.52 & -0.08 & 106.20 & 3.09 & 1 & 4429.4 \\
\hline 75 & 7.5 & 3044.55 & 0.18 & 107.87 & 0.21 & 1 & 4965.5 \\
\hline 100 & 10 & 3420.44 & 0.97 & 112.94 & 2.49 & 1 & 6605.5 \\
\hline \multicolumn{8}{|c|}{ Applying a minimum 4\% Void Space Limit } \\
\hline 30 & 3 & 2892.57 & 0.60 & 106.20 & 4.01 & 1 & 4414.1 \\
\hline 50 & 5 & 3135.08 & 0.94 & 109.62 & 4.95 & 1 & 5342.6 \\
\hline 100 & 10 & 3651.21 & 0.95 & 116.07 & 4.23 & 1 & 7866.8 \\
\hline
\end{tabular}




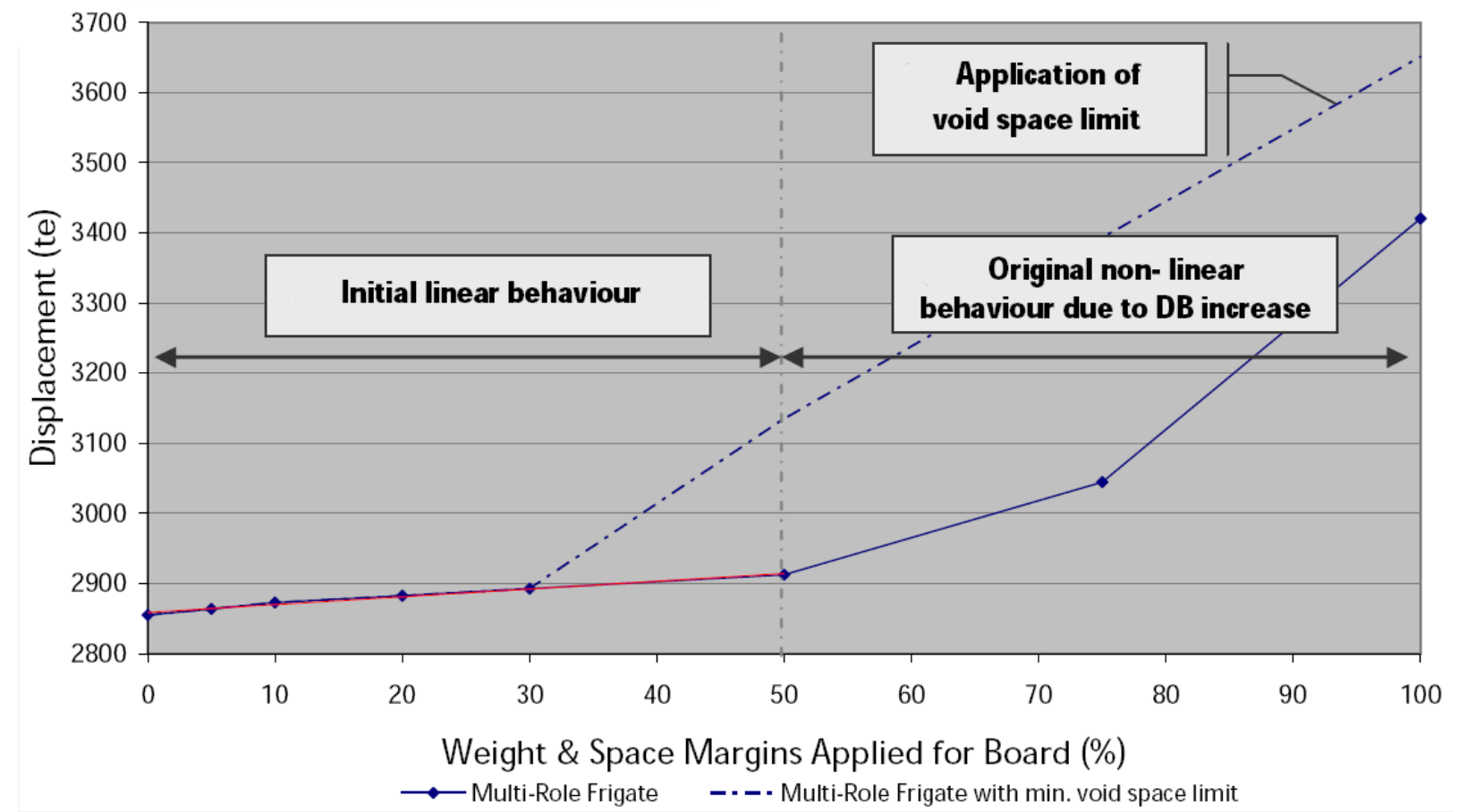

Figure 11 Ship Growth due to Board Margin variation for the Fight Functional Group for Multi-Role Frigate (Percival 2010)

Once the Board Margin exceeds $50 \%$ of the Fight elements, then ship displacement increases, requiring a larger double bottom depth due to increase in hull depth to achieve greater ship enclosed volume. As such the ship growth profile displays a non-linear behaviour in this region, due to the second order effects of the Fight and Infrastructure weight and space which then lead to needing greater buoyancy, increased hull depth and selection of larger double bottoms. The impact of including a space element for the Board Margin is readily apparent. As margin values increase, the remaining void space of each ship variant reduces accordingly, until negligible voids remain at a $75 \%$ of Fight margin value. This situation is however unrealistic for practical ship features and layout implications. As such it was decided to set a minimum acceptable limit for remaining void spaces ${ }^{1}$. The balancing process for subsequent generation of design variants was therefore conducted to achieve this volume value. This design standard was seen to generate a linear ship growth profile, albeit at an increased rate of change once the margin values were significant enough to influence total displacement.

\footnotetext{
${ }^{1}$ Current UCL practice in the MSc Ship Design Exercise suggests a $2.5 \%$ void space figure (UCL, 2010). A $4 \%$ minimum void space limit was chosen for this investigation in order to augment the UCL figure to account for the limited level of DBB detail within the reference models, when compared to the UCL MSc ship design studies - typically developed to a "shallow" feasibility level on study completion.
}

The Board Margin investigation for the original MultiRole Frigate clearly demonstrated a linear response to Board Margin increase, in terms of both weight and space. The resultant ship growth profile was not found to be dominated by any significant design changes, so no discontinuous features were found. With Board Margins applied to only the Fight and Infrastructure groups, the influence on overall ship growth remained fairly limited, until the application of margin values at levels which significantly affect ship size.

\section{Variation of Board Margin for Minimal Superstructure Frigate}

Seven variants of the Minimal Superstructure Reference Ship were produced for incremental variations of Board Margin, applying both weight and space margin elements. The Board Margins under consideration ranged from no allowance to provision for a $100 \%$ increase in Fight demands. Again a 10:1 ratio was used to incorporate possible Infrastructure impacts as a result of the Fight enhancement. Key ship particulars for these results are provided in Table 9, with more detailed results in Percival (2010). These overall ship growth results are illustrated in Figure 12, which shows linearity below the level where architecturally driven change occurs. Once architectural input is applied to maintain sensible double bottom heights then the rate of ship growth noticeably increases. 
Table 8 Results for Board Margin variation for Minimal Superstructure Frigate (Percival 2010)

\begin{tabular}{|c|c|c|c|c|c|c|c|}
\hline \multicolumn{2}{|l|}{ Minimal Superstructure Frigate } \\
\hline $\begin{array}{c}\text { FIGHT } \\
\text { Margin } \\
\text { Value (\%) }\end{array}$ & $\begin{array}{c}\text { INFRA } \\
\text { Margin } \\
\text { Value (\%) }\end{array}$ & $\boldsymbol{\Delta}$ (te) & $\begin{array}{c}\text { Weight } \\
\text { Balance } \\
\text { Achieved (\%) }\end{array}$ & LWL (m) & $\begin{array}{c}\text { Volume } \\
\text { Balance } \\
\text { Achieved (\%) }\end{array}$ & $\begin{array}{c}\text { No. } \\
\text { Passing } \\
\text { Decks }\end{array}$ & $\begin{array}{c}\text { Max } \\
\text { Range } \\
\text { (nm) }\end{array}$ \\
\hline 0 & 0 & 3302.42 & 0.77 & 99.21 & 7.73 & 2 & 5886.2 \\
\hline 5 & 0.5 & 3346.43 & 0.74 & 99.64 & 12.44 & 2 & 6096.0 \\
\hline 10 & 1 & 3385.72 & 0.68 & 100.00 & 9.03 & 2 & 6280.3 \\
\hline 20 & 2 & 3430.18 & 0.46 & 100.37 & 8.99 & 2 & 6174.6 \\
\hline 30 & 3 & 3490.58 & 0.27 & 100.89 & 8.23 & 2 & 6435.7 \\
\hline 50 & 5 & 3530.67 & -0.30 & 101.08 & 7.61 & 2 & 6532.9 \\
\hline 100 & 10 & 3870.99 & -1.21 & 103.91 & 6.61 & 2 & 7719.4 \\
\hline
\end{tabular}

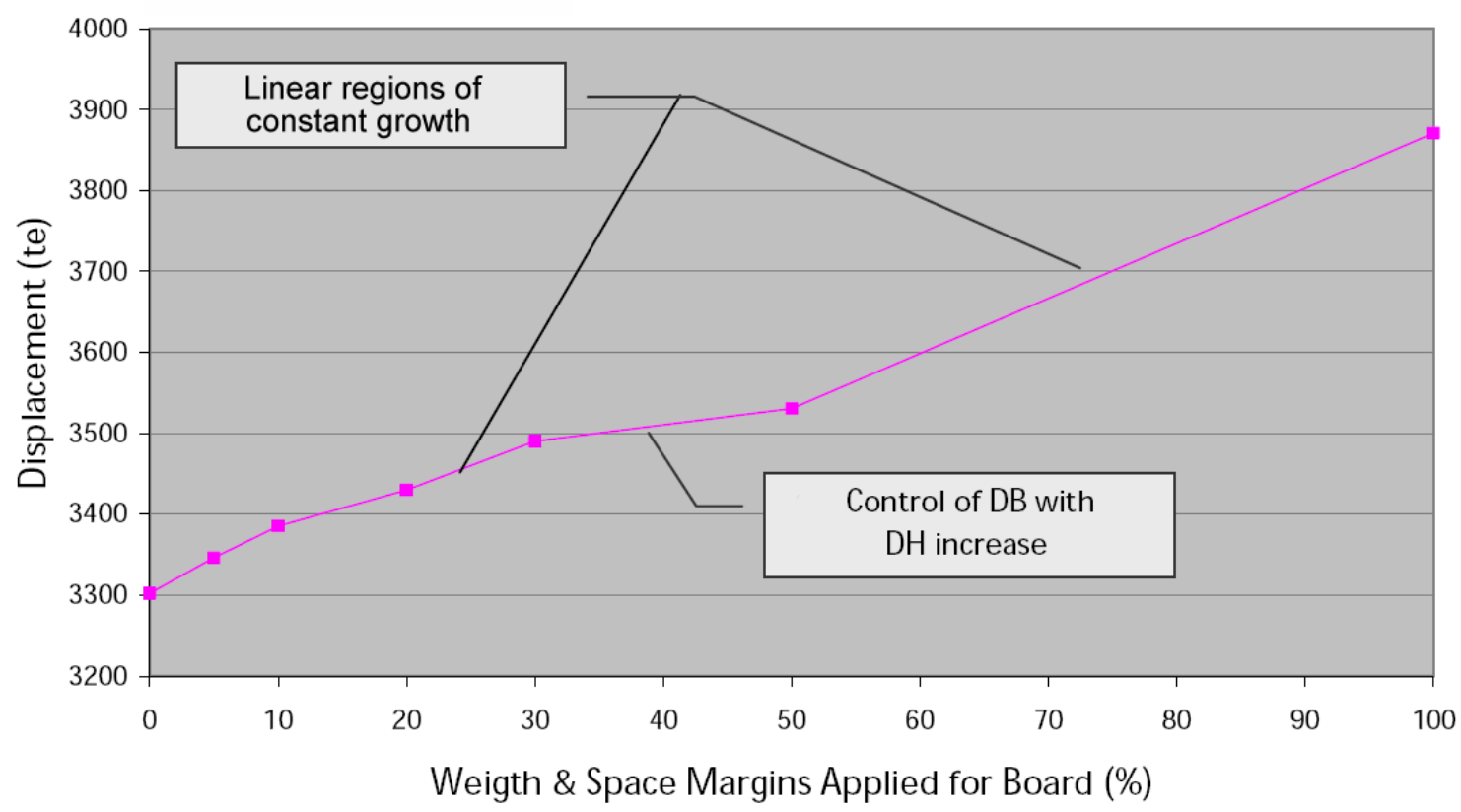

Figure 12 Ship Growth due to Board Margin variation in the Fight Functional Group for a Minimal Superstructure Frigate (Percival 2010)

In this case, the inverted plateau and cliff behaviour of the minimal superstructure design is apparent, with two extended cliff regions bounding a minimal central plateau. The apparent linearity of the result is considered reasonable due the consistency of balance achieved across the variants (i.e. $1.88 \%$ for weight balance). The 'generous' architectural characteristic of the minimal superstructure frigate provides ample void space. A proportion of this available volume could therefore be allocated to accommodate the increasing spatial demands of the Fight and Infrastructure groups, even for higher margin values, without compromising the feasibility of realistic general arrangements. This was shown by the slow decrease in void space for the higher displacement variants.

\section{Comparison of Board Margin Influence for Differing Reference Models}

Comparison of the overall ship size growth with Board Margin changes for the two reference ship designs confirms certain significant features:-

i. The rate of ship growth for the Minimal Superstructure version initially exceeds that of the Multi-Role version. This is as a direct result of the significant difference between the displacement of the two ship styles, the linear application of the margin thus driving more rapid growth for the larger (minimal superstructure) ship.

ii. Little architectural intervention to achieve a practical layout for the margin variants was 
required for the Minimal Superstructure frigate, due to its generous void space provision.

Conversely, the less spacious Multi-Role Frigate design became increasingly driven by spatial requirements due to the allocation of increased Board Margin to the Fight Functional Group.

Consideration of the values of the original reference ship displacement yields interesting results in terms of applying increases to Board Margin. In both cases the use of a more selective approach than normal practice to Board Margin allocation (i.e. to the Fight function rather than to the whole ship) provides substantial design options for future enhancement of the Fight functional group (where, arguably, it will be most valuable). The level of this potential (detailed in Table 10) provides a strong argument for this selective approach to Board Margin application, rather than the traditional numeric application to overall ship weight and space (see Table 10 for a $3 \%$ equivalent applied just to overall ship weight).

Table 10 Potential Board Margins available (Percival 2010)

\begin{tabular}{|c|c|c|}
\hline \multirow{2}{*}{$\begin{array}{c}\text { Reference } \\
\text { Ship }\end{array}$} & \multicolumn{2}{|c|}{$\begin{array}{c}\text { Potential Board Margin Values to } \\
\text { achieve a displacement equivalent to } \\
\text { the original global Board Margin (3\% } \\
\text { weight only) }\end{array}$} \\
\cline { 2 - 3 } & $\begin{array}{c}\text { FIGHT Board } \\
\text { Margin (weight } \\
\text { \& space) }\end{array}$ & $\begin{array}{c}\text { INFRA Board } \\
\text { Margin (weight \& } \\
\text { space) }\end{array}$ \\
\hline $\begin{array}{c}\text { Multi-Role.v1 } \\
\text { Frigate }\end{array}$ & $\sim 37 \%$ & $\sim 4 \%$ \\
\hline $\begin{array}{c}\text { Minimum } \\
\text { Superstructure } \\
\text { Frigate }\end{array}$ & $\sim 28 \%$ & $\sim 3 \%$ \\
\hline
\end{tabular}

\section{INSIGHTS ON THE NATURE OF CONCEPT SHIP DESIGN EVOLUTION}

\section{Key Observations}

The Board Margin investigation for the Multi-Role Frigate study exhibited linear growth. It did not reveal any step changes or cliff effects in the growth because no significant design changes were forced on this design by the margin changes introduced in this part of the overall investigation. (Interestingly, it was only in the numerically greater margin studies not reported here (see Percival 2010) that cliff effects occurred. This occurred due to significant design changes resulting in major consequences, such as the addition of second passing deck over the machinery spaces.)
Conversely, the plateaux behaviour for the Minimal Superstructure styled baseline was dominated by the cliff regions, where growth rate increased significantly in response to minor structural changes This occurred both in the investigations considering weight alone and also when spatial demands were included. This suggests that the Minimal Superstructure variant was more sensitive to variations in weight margin. This is perhaps to be expected for the larger ship, however the extent of the contrast is seen to widen under the influence of increasing deck topology demands.

The addition of Board Margins at a ratio of 10:1 to Fight and Infrastructure functional groups, respectively, was done to reflect some increase in Infrastructure weight and space consequent on Fight enhancement due to the possible requirement for increased support functions (such as increased stores capacity or additional operators). It was therefore difficult to identify a suitable ratio and the figure was somewhat arbitrarily selected at a tenth of that increase allocated to the Fight margin. This assumption of the relationship between Fight and Infrastructure components could be compared for its impact against the usual practice of Board Margin being applied as a proportion of the whole ship's weight and space. It was novel to apply the Board Margin to specific areas, rather than using the standard ship wide application, and this was seen to afford significant savings in the resulting growth in ship size, as well as provided scope for substantial enhancement to specific capabilities without adversely impacting on overall ship size.

While the concept of space allowance was adopted during this investigation, the means of application was again perhaps not truly reflective of the intent behind a Board Margin. Assuming that capability enhancement will necessitate a greater volume to house the improved system is seen to be a very simplistic, and frequently questionable, view. It could instead be argued that it is in the provision of flexible 'room for future enhancement' that the intent, behind allocating a Board Margin, would best be achieved. This is consistent with the concept that, for the Royal Navy's ships, Board Margins were historically within the gift of the Admiralty Board in allowing a new design at its approval by the Board to be given the capability to be able subsequently in service to be able to accommodate, as yet undefined, features. This higher level function of a Board Margin, could be seen to be compromised by the approach adopted in this investigation, unless some unassigned flexible space within the General Arrangement was also incorporated for such unplanned enhancements. The challenge would then be one of retaining this space during the hard-fought iterative cost-capability trade-offs that typify acquisition projects. Unless Life Cycle Cost is given true parity in major cost trade offs, Board Margin are always hard to sustain (see Brown \& Andrews (1981) for historic lessons). 


\section{Comparison of Results}

At this point, it is prudent to compare the results obtained with relevant data published in Andrews' original (purely numerical) study in 1987. Specifically the results of that Board and Growth Margin investigation can be compared with those generated during this recent exercise.

As can be seen by comparing Figures 12 and 13, there were clear similarities for the results of weight margin variations for the two investigation, separated by nearly

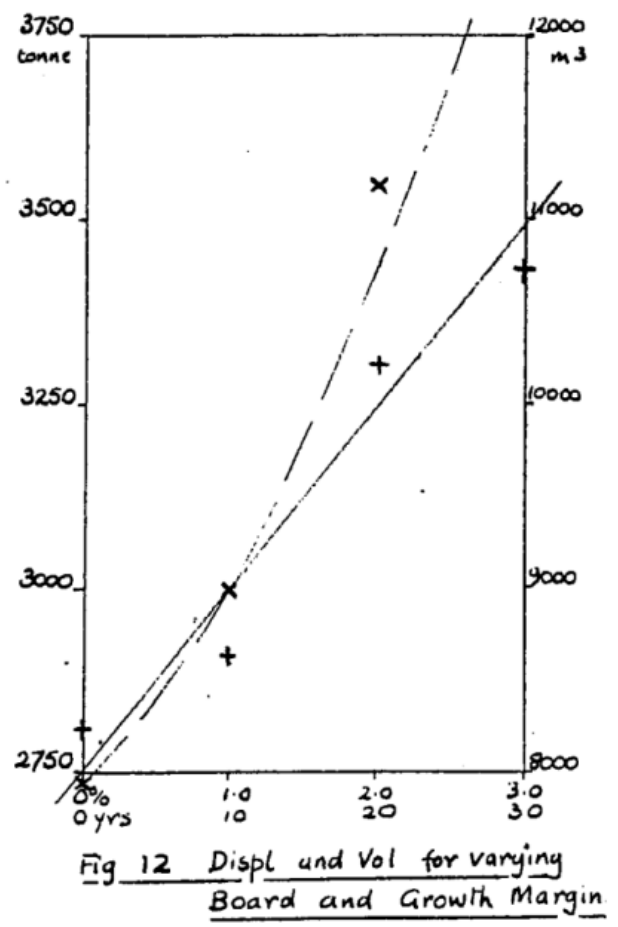

Figure 12a Ship Growth due to Weight Margin Variation using a Numerical Method (Andrews 1987)

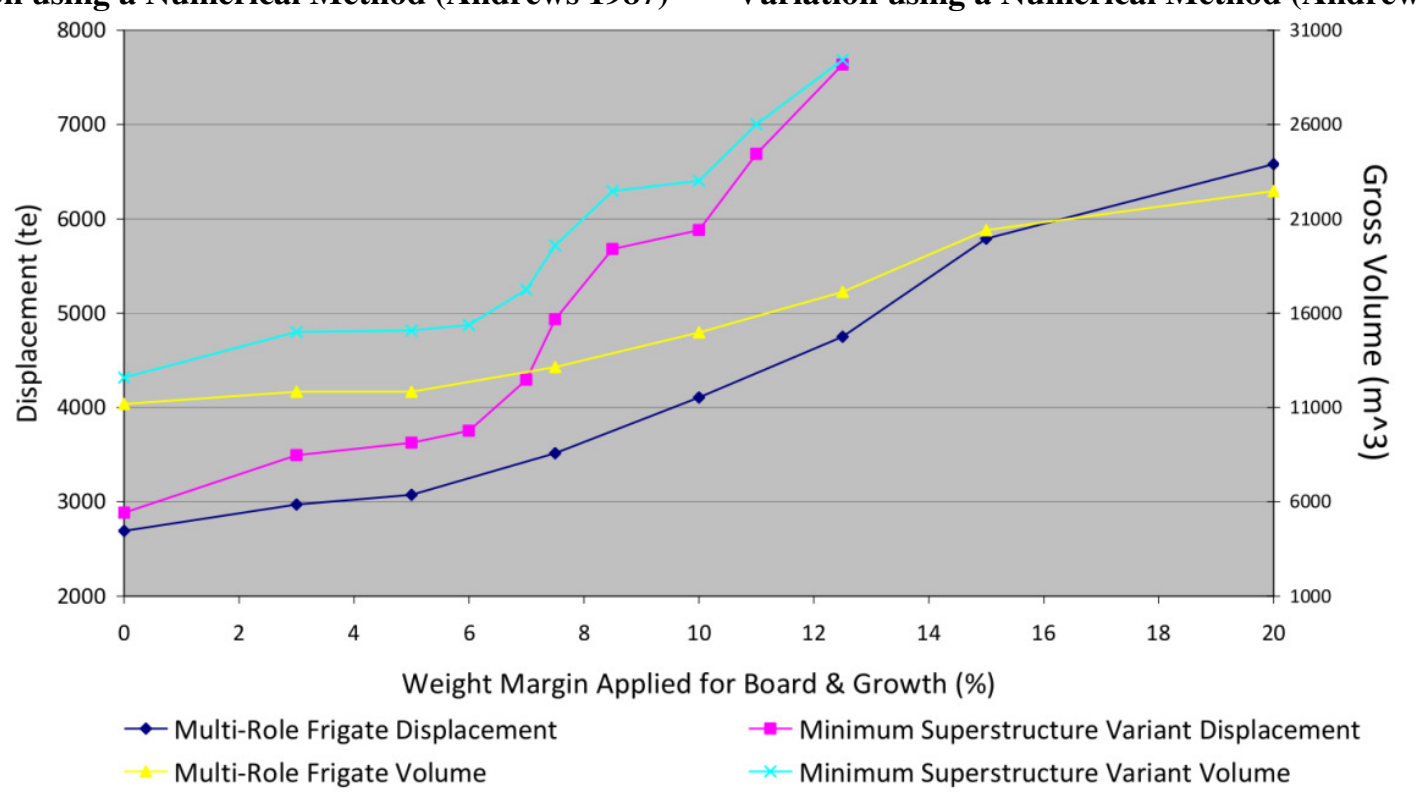

Figure 13a Ship Growth due to Weight Margin Variation using an Integrated Design Method (Percival 2010) thirty years. The marked linearity of the earlier displacement results was not however present in the newly generated profiles. This is due to the presence of cliffs and plateaux in the latter results, as is revealed by the DBB design approach. There is a marked similarity between the two sets of data presented in Figures 12b and 13b. While the numerical analysis Andrews applied in 1987 to variation in Board Margin only considered it as a weight allowance, both plots depict clear linear behaviour, thus confirming the linear behaviour of the space demand also.

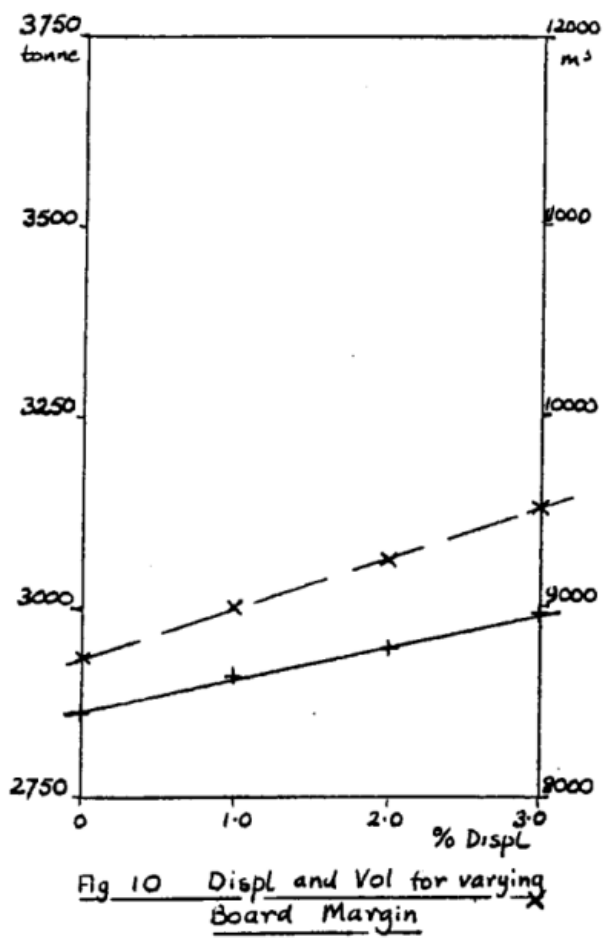

Figure 12b Ship Growth due to Board Margin Variation using a Numerical Method (Andrews 1987)

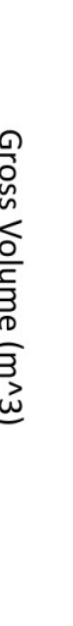




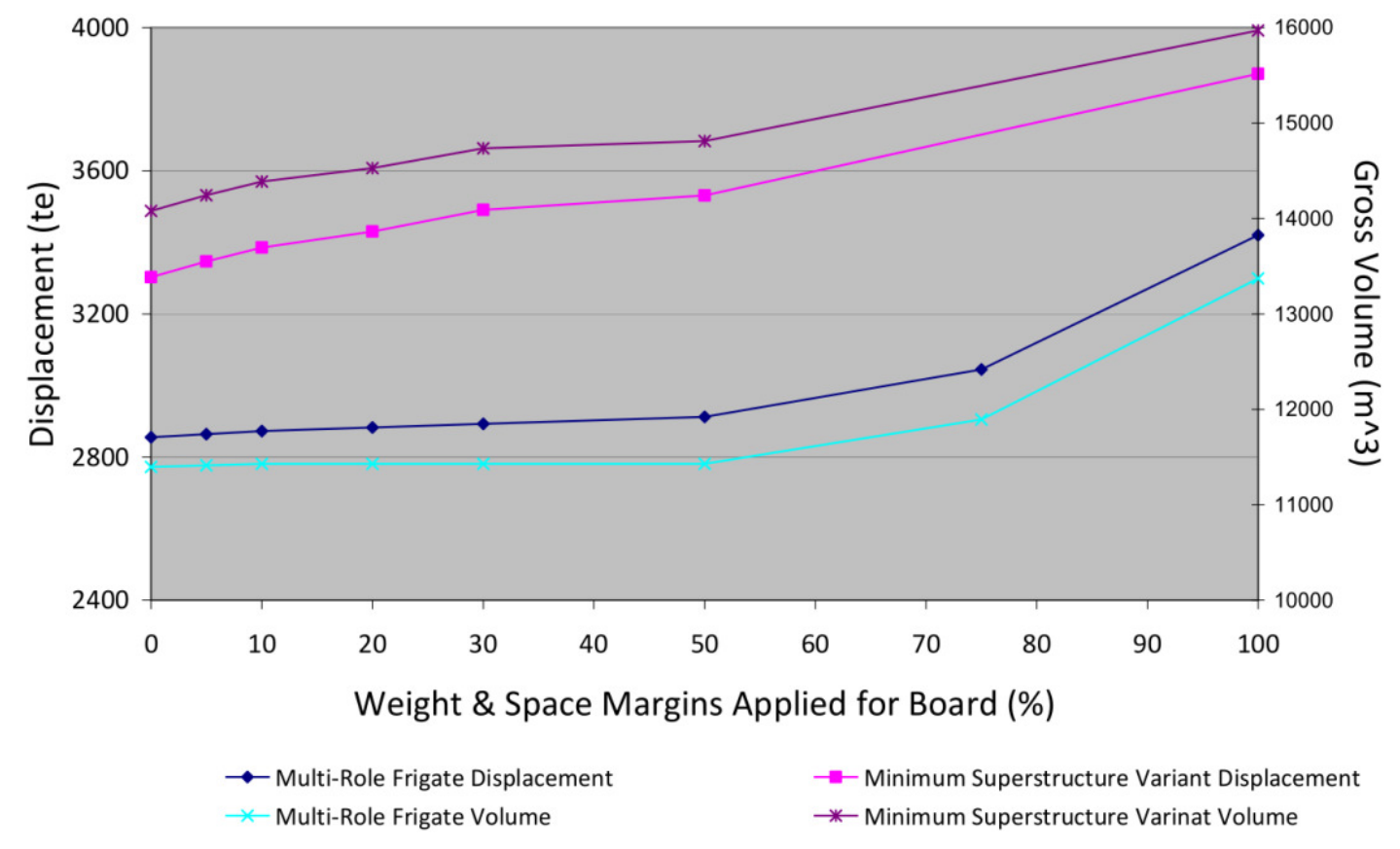

Figure 13b Ship Growth due to Board Margin Variation using an Integrated Design Method (Percival 2010)

Therefore it can be surmised that both the numerical and an integrated architectural approaches successfully captured the overall ship size growth trends of the margin investigations. However it is also clear that the level of additional detail revealing actual design cliffs and plateaux with margin growth that is only possible through use of an integrated design tool, such as SURFCON which enables the UCL DBB approach to be used within the Paramarine ship design tool.

\section{Validity of Assumptions and Limitations of the Study}

In evaluating the investigation methodology it is necessary to review the assumptions made therein. Table 7 illustrates the assumptions adopted during these investigations. These assumptions relate to compromises made when developing the early Super Building Block model, which in turn would require close consideration in subsequent stages of design development. However, for the purposes of the margins investigation, the impact of these assumptions was not fully considered.

Furthermore the impact of a Design Point $^{2}$ was not evaluated within this study. During variant generation, structural weight fraction was kept constant. Arguably this particular aspect could have been reviewed in each case to take account of the bending strength of each new hull. This would have enabled a subsequent review of structural weight, which may have resulted in differing displacements. However, it was felt that this level of

\footnotetext{
${ }^{2}$ Andrews defines the Design Point as a 'point of time in the future for which the ship is designed' (Andrews 1984).
}

structural consideration was not commensurate with the limited detail of the reference models. However, it would have been necessary to incorporate a review of the structural style into the DBB model if the reference ships being compared had been significantly different in terms of hull configuration (e.g. SWATH or Trimaran vs. monohull) or structural style.

The main limitation of the modelling approach used in this investigation is that the occurrence of cliffs was subject, in part, to the decision of the designer. Alteration of variables within the iteration process was constrained by common practice for double bottom and deck head height clearances, as well as adopting typical hull form parameters. Efforts were made to apply consistent design changes across the variants, however it remains likely that a certain level of inconsistency might well have occurred and could have altered the growth in ship size, used to assess design impact.

Within the structure of the SURFCON-Paramarine design suite it should be possible to generate a model which uses logic functions to automate some of the parameter selection (for example the use of a limit to deck height to automatically force a step change in hull dimensions). However such constraints would require complex modelling and lose the advantage of designer decision making, which is inherent in the DBB approach.

\section{Implications for Understanding the Preliminary Ship Design Process}

The power of the DBB approach in such investigations lies with the potential for further systematic research into the multitude of diverse design features and disciplines 
involved in the ship synthesis environment. Such research would inform multi-layered and interactive investigation of design influences. This intent would require considerable effort by designers to provide insights into design drivers, potential synergies and the risks associated with areas of design instability.

Reflecting again on the complexities of the 'satisficing' process (Simon 1980) that essentially governs ship design, an alternative view of the use of influence modelling becomes apparent. As stated by Purvis (1974) at the head of his major review of post-war British vessels, naval ship design is complex process of compromise. It could therefore be argued that the role of the ship designer is to identify and mitigate the 'weak-spots' generated as a byproduct of these compromises. Understanding the influence of design drivers within ship synthesis might enable achieving a higher level of design balance, in which each design variable is pushed to the limit before it becomes a dominant driving influence. In such cases certain design cliffs may be less sharply defined.

\section{Advantages of the DBB Approach}

The use of the DBB approach for generating numerous ship variants proved particularly effective. Although traditional numerical techniques would have facilitated equally rapid re-balancing for changes in weight and space demands, the topological emphasis of the DBB method provided invaluable insight into other, higher order design impacts that may otherwise have remained hidden in a simple numerical analysis. As such the DBB approach is inherently suited for use in such sensitivity studies, where influence within the holistic synthesis process must be quantified.

Conversely, as discussed by Pawling (2007), the multiple layers of potential variant generation enable the designer to incorporate innovative and creative choices when exploring alternative configurations. The development of the second reference ship during this exploration, was an example of exploiting this flexibility. While the main requirements remained unchanged, the introduction of the stylistic choice to reduce superstructure volume through commensurate increase in the main hull, produced a significantly different frigate design with different outcomes in the margin variant investigation.

However, the conclusion of the initial model evaluation stage illustrated the key limitation of the DBB approach: the accuracy of the model is intrinsically linked to the level of building block refinement within it. Admittedly the rapid generation of variant designs is viable for models of relatively crude composition, however it is a misnomer that such 'rapid' analysis can be achieved for models of, even, intermediate design definition. While such a model could be rapidly re-balanced in terms of traditional audit items (such as stability and hull resistance), any subsequent re-design of arrangement for the allocation of margins to specific functions will depend on the level of detail and will lack those insights provided by the architectural elements.

One clear feature argued from this study has been long seen as desirable in computer aided ship design, namely, the provision of an automatically generated logbook. This would provide inexperienced designers with an invaluable tool when reviewing and reassessing previous design decisions and provide an audit trail when used in anger. Given the interrelation between so many functions, such audit trails would be particularly helpful in identifying sources of unexpected or undesired changes to the model and further assist in better design assurance in early design decision making.

\section{CONCLUSION ON DESIGN SPIRAL VALIDITY}

This investigation has used the UCL Design Building Block approach to understand better the ship design process by considering the manner in which choice of margins leads to non-linearities in design evolution. In so doing it has shown the closed sequential iterative model of the Design Spiral to be too simplistic. While there are several versions of the Design Spiral they suffer from a description of ship design, both of the overall process and of the initial iterative balance, that does not allow for the complex interaction between the numerical weight and space synthesis and the practical constraints revealed by an architectural description. If the architectural aspect can be used as an integral part of the synthesis and the subsequent design evolution then it is seen that the simple repetitive spiral is misleading at both the strategic and detailed iterative levels of ship design.

Although a specific example has been used to investigate the non-linearity of designing to achieve a naval architectural balance, the proposal that the Design Spiral model is not a good representation of the ship design process has been essentially shown by this investigation. It has also been seen to be too simplistic when applied to the overall process and certainly to the more sophisticated integrated ship synthesis summarised in Figure 7. Considering the two aspects of ship design identified at the end of the second section of the paper - the iterative and interactive - only the first is caught by the Design Spiral. Even then this can be seen to only apply at the very specific eighth step of Figure 1 (and really just the numeric version of this - Figure 2) and even this is a crude representation of that sizing process. It lacks the flexibility, remarked on by Brown quoted at the beginning of the fourth section, and the human input even in a numeric process and certainly essential if a more architecturally based synthesis is undertaken.

There are other models of the process (many described in the 2009 IMDC SoA design methodology report (Andrews et al 2009)) but all seem to have their 
limitations. This is considered explicable in that the characteristic of initial ship design is complex, even for conventional vessels, such as monohull naval combatants, which could be regarded as a well-established or stable design type.

Given the inherent complexity, which is further compounded if novel ship types and hullforms continue to be considered, then it is worth asking how the ship design process ought to be modelled. (It is taken as axiomatic that it is worth using models of the ship design process not just for teaching new designers but also as a basis against which new processes and tools could be assessed.) It is concluded from studies, such as that described in this paper, that:

a. Models of the ship design process should be sufficiently strategic in representing the activities undertaken by the designer or design team, rather than just giving a direct technical procedure. Thus a description such as that summarised by Figure 1, in showing the choices that are made or constrain the process, needs to overlay any more detailed and specific description, such as Figure 7.

b. Models of the process need to directly take into account the issues usefully combined under the term "Style", as these have a major impact on the solutions produced. This paper addressed this at two levels, one was that of configurational choice while the second was the specific issue of margins for future enhancement (Board Margin in UK naval practice). The configurational issue was addressed by having the investigation duplicated for a "conventional" monohull and a minimal superstructure styled monohull. It could easily have been extended to see if, say, the same pattern arose with more radical hull forms, such as trimaran, catamaran or SWATH. The example of Board Margin was useful but there are clearly other design choices which might have been considered, such as design robustness, commercial vs. naval design practice, short life utility style vs. long life high sustainability or a "green" emphasis, to take a few of many possibilities.

c. Models need to be able to address architectural effects if they are to represent the nature of the complexity of choices. This then raises doubt over purely numeric based modelling, such as Keane et al (1991), Vasudevan (2008) and even McDonald (2010), although the latter acknowledged this (see Figure 12 in McDonald et al (2012) which suggests how the numeric library method could be combined with the DBB approach).

d. Only in reflecting the multifaceted nature of ship design, i.e. weight and space balance, naval architectural performance aspects (" $S$ ") ) and the ship architectural nature, can the sophistication of ship design be properly caught. As Graham stated:

“.. todays' warships are the most complex, diverse and highly integrated of any engineering systems produced on a regular basis." (Graham 1982)

So we should not expect to find any model of the process to be definitive and need to approach understanding the ship design process with some degree of caution, as is caught by the five desirable features, for any early stage ship design method or tool, as listed in the second section.

\section{AKNOWLEDGEMENT}

The authors would like to acknowledge the thought provoking comments from the referees, which have helped clarify our argument, however the views expressed remain those of the authors, who acknowledge UCL's permission to publish.

\section{REFERENCES}

ANDREWS, DJ, (1981), "Creative Ship Design", Trans. RINA, Vol.123, London: RINA

ANDREWS, DJ, (1984), Synthesis In Ship Design, Ph.D. Thesis, London: University of London

ANDREWS, DJ, (1987), "Explorations Into the Nature of Frigate Preliminary Design", Proc. Warship 1987: International Symposium on ASW, May 1987, London: RINA

ANDREWS, DJ, (1994), "Preliminary Warship Design", Trans. RINA, Vol.136, London: RINA

ANDREWS, DJ, (1996), "Trireme to Trimaran - the Fascination of Ship Design", Journal of Naval Engineering, Vol. 36, Book 2, June 1996

ANDREWS, DJ, (2011), "Marine Requirements Elucidation and the Nature of Preliminary Ship Design", International

Journal of Maritime Engineering, 153 (Part A1): 23

ANDREWS, DJ, (2003), "A Creative Approach to Ship Architecture", International Journal of Maritime Engineering, Vol.145, No.3, London: RINA

ANDREWS, DJ, (2012), "Art and Science in the Design of Physically Large and Complex Systems", Proceedings of the Royal Society A, published online 7 December 2011 ANDREWS, DJ (2013), "The True Nature of Ship Concept Design - And what it means for the Future Development of CASD", COMPIT2013, Cortona, Italy, April 2013.

ANDREWS, DJ, BROWN, DK (1982), "Cheap Warships are not Simple", Symposium on Ship Costs and Energy, New York, Sept 1982, SNAME, (Reprinted in Journal of Naval Engineering, 1984)

ANDREWS, DJ, DICKS, C, (1997), "The Building Block Design Methodology Applied to Advanced Naval Ship Design", Proc. IMDC 1997, Newcastle 
ANDREWS, DJ (Ed), ATLAR, M, DRAKE, K, GEE, N, LEVANDER, KJ, SEN, P, SNAITH, GJ, (1997), "IMDC State of the Art Report on Design Methods", Proceedings of IMDC 1997, Vol.2, Newcastle: University of Newcastle

ANDREWS DJ, BURGER D, ZHANG JW, (2005), "Design for Production using the Design Building Block Approach", International Journal of Maritime Engineering, Vol 147, RINA

ANDREWS, DJ (Ed), KEANE, RG, LAMB, T, SEN, P, VASSALOS, D, (2006), "IMDC State of the Art Report on Design Methodology", Proceedings of IMDC 2006, Ann Arbor, MI: University of Michigan

ANDREWS, DJ (Ed), PAPANIKOLAOU, A, ERICHSEN, S, VASUDEVAN, S, (2009), "IMDC State of the Art Report on Design Methodology", Proceedings of IMDC 2009, Trondheim, Norway

ANDREWS, DJ, PAWLING, RG, (2003), "SURFCON A 21st Century Ship Design Tool", Proc. IMDC 2003, Athens: IMDC

ANDREWS, DJ, PAWLING, RG, (2006), "The Application of Computer Aided Graphics to Preliminary Ship Design", Proc. IMDC 2006, Ann Arbor, MN

ANDREWS, DJ, PAWLING, RG, (2008), “A Case Study in Preliminary Ship Design", IJME, Vol 150, Part A3, RINA

ANDREWS, DJ, PAWLING, RG, (2009), "The Impact of Simulation on Preliminary Ship Design", Proc. IMDC 2009, Trondheim

BROWN, DK, (1986), "Defining a warship", Naval Engineers Journal, Vol. 98, Issue 2, ASNE

BROWN, DK, ANDREWS, DJ, (1981), "The Design of Cheap Warships", Journal of Naval Science, Vol.7, No.2, pp.81-95, Orpington, Kent: Defence Research Information Centre (DRIC)

BRYSON, L, (1985), "The Procurement of a Warship", Trans. RINA, Vol.127, London: RINA

BURCHER, RK, RYDILL, L, (1990), Concepts in Submarine Design, Cambridge University Press, Cambridge

DICKS, CA, (1999), Preliminary Design of Conventional and Unconventional Surface Ships Using a Building Block Approach, $\mathrm{PhD}$ Thesis, Dept of Mechanical Engineering, UCL, 1999

EAMES, ME, DRUMMOND, TG, (1977), "Concept Exploration - An Approach to Small Warship Design”, Trans RINA, Vol. 119.

EVANS, JH, (1959), "Basic Design Concepts", US Naval Engineers Journal, Vol 71, No 4, Nov 1959, ASNE

GARZKE, WH, KERR, G, (1985), "A New Warship Design Strategy - A Perspective”, Trans. SNAME, 1986.

GATES, PJ, (1986), "Cellularity: An Advanced Weapon Electronics Integration Technique", Trans. RINA, Vol. 128

GRAHAM, C quoted in GATES, PJ, RUSLING, SC, (1982), "The Impact of Weapons Electronics on Surface Warship Design", Trans. RINA, Vol.124, London: RINA
HONNOR, AF, ANDREWS, DJ, (1982), - "HMS INVINCIBLE - The First of a New Genus of Aircraft Carrying Ships", Trans RINA 1982.

KEANE, AJ, PRICE, WG, SCHACHTER, RD, (1991), "Optimization Techniques in Ship Concept Design", Trans. RINA, Vol.133, London: RINA

LEOPOLD, R, REUTER, W, (1971), "Three Winning Designs - FDL, LHA, DD-963: Method and Selected Features", Trans. SNAME, Vol.79, Jersey City, NJ: SNAME

MACCALLUM, KJ, DUFFY, A, (1987), 'An Expert System for Preliminary Numerical Design Modelling', Design Studies, Vol. 8, No. 4, October 1987

MCDONALD, T, (2009), A Library Based Approach for Exploring Style in Preliminary Ship Design, PhD Thesis, Dept of Mechanical Engineering, UCL, 2009

MCDONALD, T, ANDREWS, DJ, PAWLING, RG, (2012), “A Demonstration of an Advanced Library Based Approach to the Initial Design Exploration of Different Hullform Configurations", Computer-Aided Design, Vol. 44, Issue 3, March 2012, pp. 209-223

MINISTRY OF DEFENCE, (2000), Stability Standards for Surface Ships, Defence Standard 02-109 (NES 109) Issue 1, Glasgow: MoD

MUNOZ, J, FORREST, C, (2002), “Advantages of Software Integration From Initial Design Through to Production Design", Proc. ICCAS, Malmo

PAPANIKOLAOU, A, (1994), 'Fishing Craft Design Methodology', WEGEMT Summer School 1994

PAWLING, RG, (2007), The Application of the Design Building Block Approach to Innovative Ship Design, PhD Thesis, Dept of Mechanical Engineering, UCL, 2007.

PERCIVAL, V, (2010), An Exploration of Design Drivers within Ship Synthesis, Dissertation for MSc in Naval Architecture, UCL, Sept 2010

PERRON, Y, (2002), The Nature of Frigate Sizing. Dissertation for MSc in Naval Architecture, UCL, 2002

PURVIS, MK, (1974), "Post War RN Frigate and Guided Missile Destroyer Design 1944-1969", Trans. RINA, Vol.115, London: RINA

RAWSON, KJ, (1986), "The Architecture of Marine Systems", IEE Proceedings, Vol 133, Part \$, No 6 Sept 1986

RAWSON, KJ, TUPPER, EC, (1976), Basic Ship Theory, (2nd Ed), Longmans, London

UCL, (2010), Ship Design Exercise Procedure, London: Department of Mechanical Engineering, University College London

UK MoD (1999) Smart Procurement Implementation Team: "The Acquisition Handbook", Edition 1 - April 1999.

VASUDEVAN, S, (2008), Utility of the Pareto-Front Approach to Elucidating Ship Requirements during Concept Design, PhD Thesis, Dept of Mechanical Engineering, UCL, 2008

WATSON, DGM, GILFILLAN, AW, (1976), "Some Ship Design Methods", Trans. RINA, Vol.119, London: RINA 


\section{APPENDIX: Description of the Steps in the Ship Design Process (Figure 1)}

a. $\quad$ Perceived Need - This should emerge from the customer's consideration of the market drivers or, in the case of naval vessels, from a threat analysis, the need to get a new sensor or weapon to sea in a new class of vessels or just the replacement of a class of ships that are reaching their end of life. This need is best approached (given the wicked nature of requirement elucidation) in broad terms: thus 'a new general combatant/fleet escort' or 'a replacement amphibious landing (dock) ship'.

b. Outline of Initial Requirements - This should also be very broad in that beyond the basic capability 'everything should be negotiable'. That is not to say that aspects, such as cost and time, are not of major importance but even these should be in the equation as the individual vessel size or style might yet be better met in a manner yet to emerge from the requirements elucidation dialogue.

c. Selection of the Style of the Emergent Ship Design - This is the first design choice - and given the exploration stage should consider a range of technological solutions, each of these may have specific styles associated with their particular technology (e.g. commercial design standards for a utility helicopter carrier (HMS OCEAN), low underwater signature for an ASW frigate (Type 23)). But also there are generic style choices, such as being robust, highly adaptable, high sustainability or low manning, which should be considered for specific concepts. While adopting such style issues is inherent in commencing any design study it is important that this is done consciously since each one has implications for the eventual design outcome and therefore ought to be investigated before that style aspect is incorporated or rejected.

d. Selection of major Equipments and Operational Sub-systems - Given an indication for a given solution type on the Concept Exploration solution space (such as a fast trimaran frigate or a utility carrier) and its appropriate performance (e.g. fleet speed, sustained endurance, maintenance standard), it is necessary to postulate from a likely ship size the likely power plant. It is also necessary to identify the likely major combat equipment or sub-systems. (Selection of standard items such as medium calibre guns or PDMS but less so if a concurrently developing major combat element, such as the PAAMS for the Type 45 Destroyer or the Towed array for the Type 23, where options may be explored. This could be just the size and split of weapon silos but more likely this would be the subject of trade off studies later in concept.

e. Selection of Whole Ship Performance Characteristics - For a naval combatant these may actually have more effect on the whole ship solution than the combat system choices. Thus classical hull form drivers of stability, resistance and seakeeping, which could be seen as emerging from the style choices above or more directly. As performance characteristics or laid down standards, like complementing 'rules' are likely to be major size and (ship) cost drivers. So again these should be open to revision - probably informed by the Concept Studies stage.

f. $\quad$ Selection of Synthesis Model - Despite the fact that this is a crucial decision, it is often made by default. Individual design organisations have their own synthesis tools and associated data-bases. These can inhibit the scope of the Concept Exploration, if for example a trimaran design cannot then be considered. As was amply demonstrated for the classical numerical synthesis sequence (Andrews 1986) there are inherent assumptions and data/rules in any approach. The real issue is that these are rarely questioned and their limitations can compromise subsequent baseline design definitions and the trade-off studies refining them and the requirements elucidation dialogue - especially if the modelling tool is a 'black box'.

g. Selection of the basis for Decision Making in Initial Synthesis - This should be a conscious choice before the (selected) synthesis modelling tool or approach is used. Again this is often made by default choice of the synthesis tool. Thus classical numeric sizing will balance an option in weight\& displacement and volume required $\&$ volume available, while subject to crude checks of stability and powering. Often the metric sought is then (an equally) crude initial (weight based) costing - or at best RFR for merchant ships. Whether this is the right basis for decision making is questionable - particularly as the main design drivers may yet to emerge (e.g. underwater noise signature, amphibious force offloading, air wing sortie rate). The more sophisticated architecturally driven synthesis realised by the UCL Design Building Block (DBB) approach opens up the synthesis and enables a Simulation Based Design practice, where the 3-D configuration can be investigated for human factors aspects or other simulations (such as D for Production, D for Support, D for Survivability ). This can then ensure that the balanced synthesis reflects more than a crude initial cost and simple stability and power checks.

h. Synthesis of Ship Gross Size and Architecture - With the initial choices consciously made the baseline and subsequent concept studies, and then the Concept Design options can be produced. Provided an architectural definition has been included in this many of the style issues and the requirement elucidation (providing the basis for the dialogue with the requirements owner or customer) can be investigated.

i. Exploration of Impact of Style, Major Equipment and Performance Characteristics Although style is seen to be the most crucial exploration, without an architecturally centred synthesis it is questionable that many style aspects can be explored at this stage. Rather most exploration tends to be focused, in the Concept Design trade off stage on 'payload' and powering. If, as well as style issues, different solution types such as SWATH and Trimaran configurations are to be properly considered in this exploration the an architecturally based approach should be employed. 
j. Selection of Criteria for Acceptance of Emerging Design - This is really setting up the basis for the Concept Design stage trade off studies and sensibly informed by the Concept Studies of what might be the crucial style choices. This should not just be dependent on the perceived overall project needs but also which of the technological (and packing/capability) alternatives have been revealed as relevant and significant to be pursued in more depth in the trade-off exercise, when agreement to proceed to the next project phase needs to be robust for high level approval.

k. Analysis of Size and Form Characteristics - If just a simple numerical synthesis has been undertaken in the Concept Studies stage then only default hull form parameters are likely to have been assumed. Before the Baseline Design for each of the (few) selected option from the wide Concept Exploration solution space from which Concept Studies have been performed, then it is necessary to conduct an investigation of the main hull dimensions and principal form parameters (typically for a monohull this includes $\mathrm{C}_{\mathrm{p}}, \mathrm{C}_{\mathrm{m}}, \mathrm{B} / \mathrm{T}, \mathrm{L} / \mathrm{D}$ and superstructure percentage). This is called a parmeteric survey at UCL which is different to US Navy practice where the same term denotes a trade-off of hull sizing. If a proper architecturally based synthesis is performed it is likely that the parameteric survey will already have been informed by the internal compartmental disposition so that overall hull sizing and shaping will merge from realistic hull form options. If not then hull form dimension and parameters will be wrongly selected and this will only be revealed later in the design development. If unconventional configurations, including multihulls, are being properly considered and then taken forward the likelihood of an unrealistic parameter selection will be even greater, weakening the conclusions from trade-off studies.

1. Architectural and Engineering Synthesis and Analysis - This step reflects the need in a given project to undertake (as part of Concept Design prior to finalising any comprehensive trade off of requirements, style, configuration, etc.) specific detailed engineering design and preliminary analysis. Such more detailed first principles design work is not undertaken comprehensively in the Concept Phase - this being the task of the early iterations of the selected Concept Design solution in the next (and subsequent) phase of design (i.e. Feasibility or Embodiment Design). However it may well be for a given project that in the concept phase, that a certain aspect needs to be investigated in more depth. (An example was conducted by the author in the early 1990s in the concept phase of what became the RFA WAVE Class Tankers. This AO was the first RFA fleet tanker required to be doubled hulled. It was therefore necessary to undertake detailed damage stability analysis of all the ships' likely operating conditions. This would not normally be required pre-feasibility and reinforces the adage that 'the minimum detailed engineering is undertaken in the concept phase' however sometimes the 'minimum' is comprehensive in a specific aspect (namely extensive damage stability here).)
The inclusion of the 'architectural element' in this step's title is deliberate as once any detailed engineering synthesis and analysis is undertaken, it must be with reference to the internal architectural arrangement or again conclusions drawn will be found to be inadequate or even misleading once Feasibility is underway.

$\mathrm{m}$. Evaluation of the design to meet the Criteria of Acceptability - This evaluation occurs both in the trade-off exercise from which the final Concept Design is selected and essentially to the subsequent design development of that design. Clearly it is necessary to have a basis for evaluation to make that selection and to spell out the criteria for acceptability. These criteria will be quite high level for the Concept Phase and of ever greater detail once downstream. Given that the task of Concept is Requirement Elucidation, it is important that the evaluation is consistent with the evolving refinement of the requirement that emerges from the dialogue with the selected Concept Design. That design provides the start point for the Feasibility Phase with the matching requirement statement providing the specification (along with associated standards and style statements) that can be used for the main design development.

n. The remaining three steps in Figure 1 indicate the rest of the design process, once the Concept Phase has been correctly conducted, and is a process of ever greater detailing of the design through the various design phases to achieve sufficient definition for building, setting to work and through life performance. Given these phases constitute the vast bulk of the time and design resources this can seem a little glib. However the point of this current exposition is to emphasise that all subsequent design is based on both the emergent concept design and the matching requirements, such that the initial process as requirements elucidation is quite different in intent and hence process. That far too many major (naval) ship designs revisit much of the concept and requirement effort is clearly indicative that the Concept Phase is too often inadequately undertaken. This is not least because all too often it is seen as the first part of the rest of the design and not the ship design half of Requirements Elucidation. 